\title{
Rigorous testing to assess the self-cleaning properties of an ultra-water-repellent silicone rubber surface
}

\author{
K. Maghsoudi*, G. Momen, R. Jafari, M. Farzaneh \\ Department of Applied Sciences, University of Quebec in Chicoutimi (UQAC) \\ 555, boul. de l'Université, Chicoutimi, Québec, G7H 2B1, Canada \\ * E-mail: Khosrow.maghsoudil@uqac.ca
}

\begin{abstract}
Ultra-water-repellent silicone-based surfaces were produced to study their self-cleaning properties. First, we investigated the consistency of the micro-nano air pockets that are present between the surface asperities responsible for the formation of the Cassie-Baxter regime. We then performed a comprehensive series of self-cleaning experiments involving both dissolved and non-dissolved contaminants using various materials (e.g., kaolin, carbon black, silica, etc.) and contaminant-applying methods (e.g., dropwise, spraying, wet or dry contaminants). In this paper, the self-cleaning tests were arranged from the less severe, i.e., nondissolved contamination tests, to more severe, i.e., wet dissolved contamination test, and ending with the most severe, i.e., dry dissolved contamination test. Due to the ultra-low contact angle hysteresis, the produced surfaces showed favorable self-cleaning properties against the various types of contaminants and the different means of contaminant application. The produced surfaces retained their water repellency properties following application of the contaminants and after the cleaning of the surfaces, thus verifying the self-cleaning performance and resistance of the fabricated superhydrophobic silicone surfaces.
\end{abstract}

Keywords: Silicone rubber, Wenzel and Cassie-Baxter regimes, Ultra-water-repellent surface, Selfcleaning, Dissolved contamination, Non-dissolved contamination, Outdoor condition

\section{Introduction}

Superhydrophobic surfaces are used in a wide range of applications in both research and industrial settings, including applications requiring anti-corrosion, icephobic, anti-fogging, anti-biofouling, oil-water separation, low-adhesion, low-drag, non-wetting, buoyancy enhancement, and self-cleaning properties. ${ }^{1-11}$ Superhydrophobic surfaces, specified by a water contact angle (WCA) $>150^{\circ}$ and a sliding angle (SA) or contact angle hysteresis $(\mathrm{CAH})<10^{\circ}$, are produced via a combination of low surface-energy material and a hierarchical micro-nanostructured surface. ${ }^{12,13}$ 
There are two main regimes for describing the wetting behavior of rough surfaces. The first is the Wenzel state $^{14}$, where a water droplet penetrates the surface features, thereby wetting the entire surface. The second is the Cassie-Baxter state ${ }^{15}$ where the water droplet rests on top of the surficial micro-nanofeatures in contact with only the peaks of the features, and air pockets are trapped underneath the water droplet. In the Cassie-Baxter state, the water droplets can roll easily due to low resistance from the entrapped air pockets, whereas in the Wenzel state, the water droplets stick to the surface structures. ${ }^{16}$ Dynamic effects of a droplet, such as impacting, bouncing, or vibrating, can lead to the transition from a solid-air-liquid interface to a solid-liquid interface. ${ }^{17}$ Therefore, the presence of the trapped air pockets and the robustness of these air pockets to dynamic water droplet effects play an important role in the formation and maintenance of the Cassie-Baxter state allowing a droplet to roll across a surface.

In addition to WCA and CAH measurements, there are several means by which the wettability properties and the dominant regime of a superhydrophobic surface can be investigated. The first approach to evaluate the robustness of the entrapped air pockets responsible for the formation of the Cassie-Baxter regime is to study the droplet impact process on an ultra-water-repellant surface. There are three scenarios whereby a Newtonian liquid droplet impacts a superhydrophobic surface: complete rebounding, partial rebounding, or shattering. The possibility for each scenario to occur depends on surface roughness, the surface tension of the liquid, and the initial kinetic energy of the droplet, all of which affect the dynamic pressure. ${ }^{18} \mathrm{Li}$ and co-workers ${ }^{19}$ investigated the influence of WCA and the roll-off angle on the dynamic characteristics of superhydrophobic surfaces having different micro-pillar arrays. They showed that $\mathrm{CAH}$ and the advancing contact angle are fundamental wetting parameters affecting drop spreading and recoiling phases. The spreading coefficient of a droplet is influenced by both the WCA and the roll-off angle (roll-off angle is defined as the inclined angle at which the droplet begins to roll off the surface), whereas the rebounding coefficient of a droplet is highly defined by the roll-off angle. ${ }^{19}$ Although in the droplet impacting process the water-repelling property of the surface cannot be measured by a specific parameter, such as WCA and $\mathrm{CAH}$, it can be a reliable representative of the wetting property of a surface. ${ }^{20}$

The analysis of droplet evaporation is a useful means of understanding natural complex systems, extending the application of water-repellent materials as well as studying the transition from a Cassie-Baxter to Wenzel state. ${ }^{21}$ As the water droplet evaporation process is controlled by the diffusion of the liquid into the surrounding atmosphere, the presence of the substrate and its topology govern the space available for the vapor to diffuse. ${ }^{22}$ Zhang and co-workers ${ }^{21}$ concluded that although microstructures reduce the contact area between water and substrate considerably and lead to air being trapped within the interface and the creating the Cassie-Baxter regime, the penetration of water vapor into the cavities can cause a transition from a Cassie-Baxter to a Wenzel state. Jung and Bhushan ${ }^{23}$ considered water droplet size and the distribution of 
geometrical parameters in establishing a criterion to predict the transition from Cassie-Baxter to Wenzel regimes. Dash and Garimella ${ }^{24}$ compared the evolution of droplet volume during evaporation off a smooth hydrophobic surface and off a hierarchical superhydrophobic surface. For a water droplet with an initial volume of $3.6 \mu \mathrm{L}$ on the superhydrophobic surface, the droplet volume after $1000 \mathrm{~s}$ was less than that on the smooth hydrophobic surface. The marble-like appearance of the water droplet until the late moments of the evaporation confirms that droplet collapse does not occur. ${ }^{25}$ Moreover, the study of superhydrophobic surface behavior against water-jet impact ${ }^{26-29}$ and severe droplet contact ${ }^{30}$, as well as the presence of the plastron layer on an ultra-water-repellant surface ${ }^{31-33}$ are some of the existing complementary experiments for evaluating Cassie-Baxter regimes on surfaces.

The self-cleaning properties of superhydrophobic surfaces have been investigated frequently. ${ }^{26,34-38}$ This property has been demonstrated for plant surfaces by Barthlott and Neinhuis. ${ }^{39}$ Over 200 plant species benefit from using rolling droplets to self-clean their surfaces. ${ }^{40}$ The most well-known of these, the lotus plant, has an intrinsic hierarchical structure on the surface of its leaves that produces a very low water CAH leading to their self-cleaning ability. ${ }^{41,42}$ Thus, self-cleaning properties, known as the "lotus effect", have influenced considerably industrial applications including self-cleaning window glasses, paints, textiles, solar panels, etc. ${ }^{42}$ Water droplets, with an almost spherical shape on superhydrophobic surfaces, carry away hydrophilic contaminants adhered to the surface when the droplets roll off the surface. This results from the stronger adhesion of the contaminant particle to the water droplet than the adhesion of the particle to the superhydrophobic surface. ${ }^{41}$ The tilted angle of a surface on which a water droplet begins to move is defined as the sliding angle (SA) or tilt angle (TA); this is in direct relation with the CAH. ${ }^{37}$ Fig. 1 shows a water droplet sliding easily across a superhydrophobic surface to carry away contaminants.

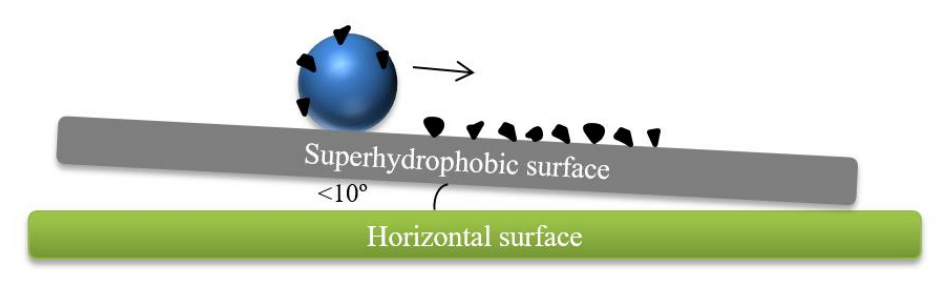

Fig. 1. Self-cleaning property of a superhydrophobic surface

A series of parameters, including surface roughness, the degree of particle adhesion and water repellency, are dominant in the self-cleaning ability of these surfaces. ${ }^{37}$ Bhushan and co-workers ${ }^{37}$ introduced a systematic study of the self-cleaning property of different nanostructured, microstructured, and hierarchically structured superhydrophobic surfaces. They observed that a droplet having nearly zero kinetic energy was unable to clean nanostructured and microstructured surfaces. However, the hierarchical 
surface was almost entirely cleaned. Bagheri and co-workers ${ }^{43}$ measured the minimum surface tilt angle needed for the appearance of the self-cleaning property of the different nanocomposite coatings. The selfcleaning characteristics of superhydrophobic coatings used for high-voltage outdoor insulators are of great importance. ${ }^{44}$ The wet pollution layer followed by dry-band formation on the insulator surface has a significant effect on the insulator pollution flashover. ${ }^{45-47}$ The IEC 60507 standard has been widely used to study the flashover performance in the artificial pollution testing of high-voltage outdoor insulators. ${ }^{48}$ There are three polluting methods used in the solid layer method of artificial pollution testing: spraying, dipping, and brushing ${ }^{49}$. Kaolin ${ }^{50,51}$, active carbon ${ }^{44}$, and $\mathrm{NaCl}$ solutions ${ }^{49}$ are some of the most common artificial pollutions applied to evaluate the self-cleaning property of the insulators.

A detailed assessment of outdoor settings reveals that there are different pollution scenarios: dry dust may be deposited onto surfaces in desert areas by the wind, or air-suspended pollution can be dissolved in raindrops and fall onto exposed surfaces. The liquid component of this latter solution may then be evaporated by solar radiation or elevated temperatures, leaving the polluted surface exposed to the next rainfall cycle. Moreover, whenever rainfall is involved, the diameter of rain droplets varies from $400 \mu \mathrm{m}$ to $\sim 2 \mathrm{~mm}$ as a function of rain rate $\left(\mathrm{mm} \cdot \mathrm{h}^{-1}\right)$, and this variability must also be considered. ${ }^{52}$

Therefore, to imitate realistic pollution scenarios that are representative of outdoor conditions, three factors must be considered: i) the condition of the contaminant as either a solid particle or a solution; ii) the method of applying the contaminant and cleaning the polluted surface, i.e., dropwise, spraying, immersion of the sample within a contaminant solution; iii) the condition of the contaminated surface before the cleaning process, i.e., has the original contaminant solution dried off the surface? Therefore, a series of self-cleaning tests can be designed using the collection of these scenarios. Given that self-cleaning studies on superhydrophobic surfaces in the literature, to the best of our knowledge, are limited to only one specific set of conditions, we felt the necessity of addressing this gap in the general knowledge of self-cleaning properties.

Here, we successfully produced superhydrophobic silicone rubber (SHSR) surfaces having a high WCA and a very low CAH. As the industrialization of superhydrophobic surfaces has attracted much attention, we used an industrialized approach to produce the superhydrophobic silicone rubber surfaces, i.e., a compression molding system and molding inserts. ${ }^{4}$ A stable interface guaranteed by the presence of micronano air pockets is necessary for ensuring a successful water-repellant surface. Therefore, it becomes necessary to study the robustness of these air pockets when evaluating their self-cleaning ability. We investigate the consistency of the Cassie-Baxter regime to create and maintain low CAH surfaces via various tests, including the droplet impacting process, the droplet evaporation measurement test, water-jet 
impact, a trapped air layer, and severe droplet contact. Based on the stability of the Cassie-Baxter regime, these surfaces show promising self-cleaning properties and a resistance to the accumulation of contaminants. We used various analyses to comprehensively assess the self-cleaning properties of the produced SHSR surfaces by manipulating the three abovementioned self-cleaning factors (Fig. 2).

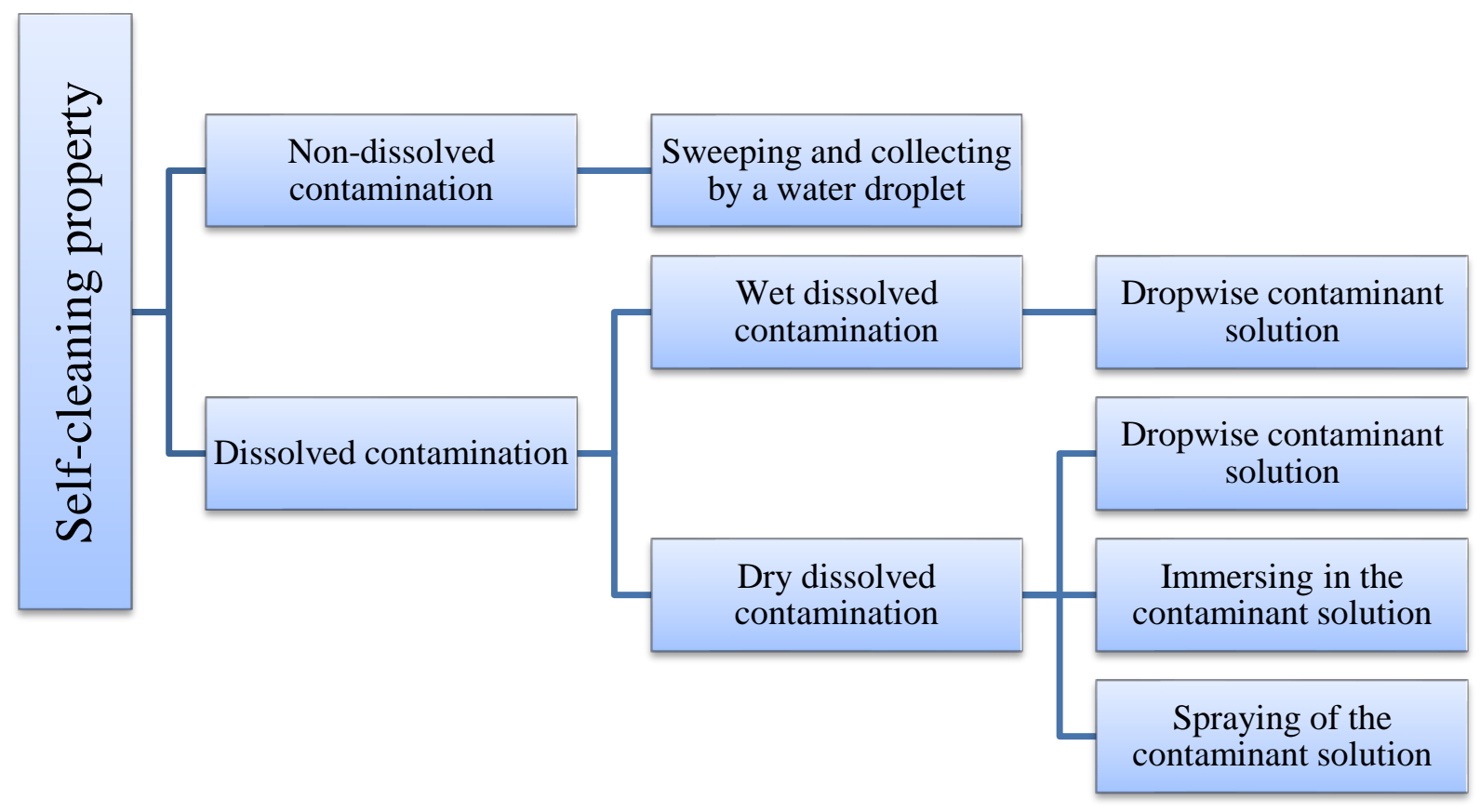

Fig. 2. Flow diagram of the multiple various tests used to evaluate the self-cleaning properties based on the conditions of contaminant deposition

\section{Materials and methods}

\subsection{Fabrication of superhydrophobic silicone rubber surfaces}

We applied a compression molding system (Carver Inc., USA) to fabricate silicone rubber having a micronanostructured surface. We used a molding insert to create the appropriate micro-nanostructured mold surface, whereas a chemical etching approach, using hydrochloric acid, created micro-nanostructures on an A6061 aluminum template. We set the etching parameters at $15 \mathrm{wt} \%$ acid solution and an etching time of $2 \mathrm{~h}$ as to obtain optimal superhydrophobic properties for the produced silicone rubber surface..$^{53}$ 


\subsection{Surface characterization}

A scanning electron microscope (JSM-6480 LV SEM manufactured by JEOL Japan) provided visual confirmation of the morphology of the produced silicone rubber surfaces. An optical profiler (Profil3D, Filmetrics, USA) measured surface roughness and the area roughness quantities were calculated based on an ASME B46.1 3D standard.

\subsection{Wettability and the Cassie-Baxter regime}

A Kruss ${ }^{\mathrm{TM}}$ DSA100 goniometer determined WCA and CAH at $25 \pm 0.5^{\circ} \mathrm{C}$. A $4-\mu \mathrm{L}$ water droplet deposited onto the sample surface allowed determining the WCA using the Young-Laplace approximation. The CAH equaled the difference between the advancing and receding contact angles when the water droplet moved across the surface. To ensure accuracy and reproducibility, we conducted WCA and CAH measurements at five different points on each sample; we reported the average WCA and CAH along with the standard deviation. The amount of surface energy was determined using the Owens and Wendt method ${ }^{54}$, and we used the surface energy parameters of water and ethylene glycol.

A high-speed camera (FASTCAM SA1.1 by Photron) recorded the process of the droplets impacting on the SHSR surfaces. The framing rate was set to $5400 \mathrm{fps}$. All experiments were carried out in a closed chamber $(60 \mathrm{~cm} \times 45 \mathrm{~cm} \times 45 \mathrm{~cm})$ at a constant temperature of $22{ }^{\circ} \mathrm{C}$. A $20-\mu \mathrm{L}$ DI water droplet having a diameter of ca. $3.4 \mathrm{~mm}$ impacted onto the surface. The surface was placed onto a flat holding device, and the water droplets were released from a height of $6 \mathrm{~cm}$. We used a syringe equipped with a needle (diameter $=0.8$ $\mathrm{mm}$ ) to create a water jet that impacted the surface under normal force. The distance and the angle between the needle tip and the surface was ca. $3 \mathrm{~cm}$ and $25-30^{\circ}$, respectively. The water jet impacted the surface at a velocity of ca. $2.5 \mathrm{~m} \cdot \mathrm{s}^{-1}$.

\subsection{Self-cleaning properties}

In the self-cleaning tests, we used two different contaminant solutions. One solution consisted solely of 40 $\mathrm{g}$ kaolin particles (ranging from $1-25 \mu \mathrm{m}$ in diameter, mean $=11 \mu \mathrm{m}$ ) as the contaminant in $1000 \mathrm{~g}$ deionized water, based on IEC standard $60507 .{ }^{48}$ The second solution was a $40 \mathrm{~g} \cdot \mathrm{L}^{-1}$ dirty solution consisting of equal amounts of $\mathrm{SiO}_{2}$ particles, carbon black, salt, and kaolin in water as a multi-contaminant solution. All solutions were mixed continuously for $1 \mathrm{~h}$ at $600 \mathrm{rpm}$ to obtain a homogenous solution before their use in the tests. A syringe having a $0.8-\mathrm{mm}$ diameter needle was used for the sweeping test. Images were captured by the Kruss ${ }^{\mathrm{TM}}$ DSA100 goniometer. An optical microscope (Nikon Eclipse E600Pol, polarizing microscope, maximum magnification $=1000 \times$ ) was used to observe the contaminant-covered surfaces. For evaluating the chemical composition of the surface, we used Fourier transform infrared 
spectroscopy (FTIR) using a Cary 630 FTIR Spectrometer (Agilent, USA) in ATR (attenuated total reflection) mode to acquire the highest quality spectra in the infrared range of $400-4000 \mathrm{~cm}^{-1}$. For the spraying contaminant test, we used an air-powered gravity-feed spray gun having a 1.0-mm diameter nozzle and applied a 15-bar pressure to spray the solution onto the surfaces. For the self-cleaning tests, a highquality digital camera (PowerShot SX50 HS, Canon) captured all images.

\section{Results and discussion}

\subsection{Fabrication of superhydrophobic silicone surface}

An obtained WCA of $166.2 \pm 1.3^{\circ}$ and CAH of $1.6 \pm 0.4^{\circ}$ demonstrated the superhydrophobic nature of the produced silicone rubber sample. The pristine silicone rubber (PSR) surface had a WCA of $116.0 \pm 2.0^{\circ}$ and CAH of $42.2 \pm 3.1^{\circ}$ demonstrating its hydrophobic properties. SEM images highlight micronanostructures on the superhydrophobic silicone rubber (SHSR) surface (Fig. 3). These micronanostructures created by a replication process are responsible for the water-repellent behavior by satisfying the required conditions of low surface energy material and roughness for achieving superhydrophobicity.
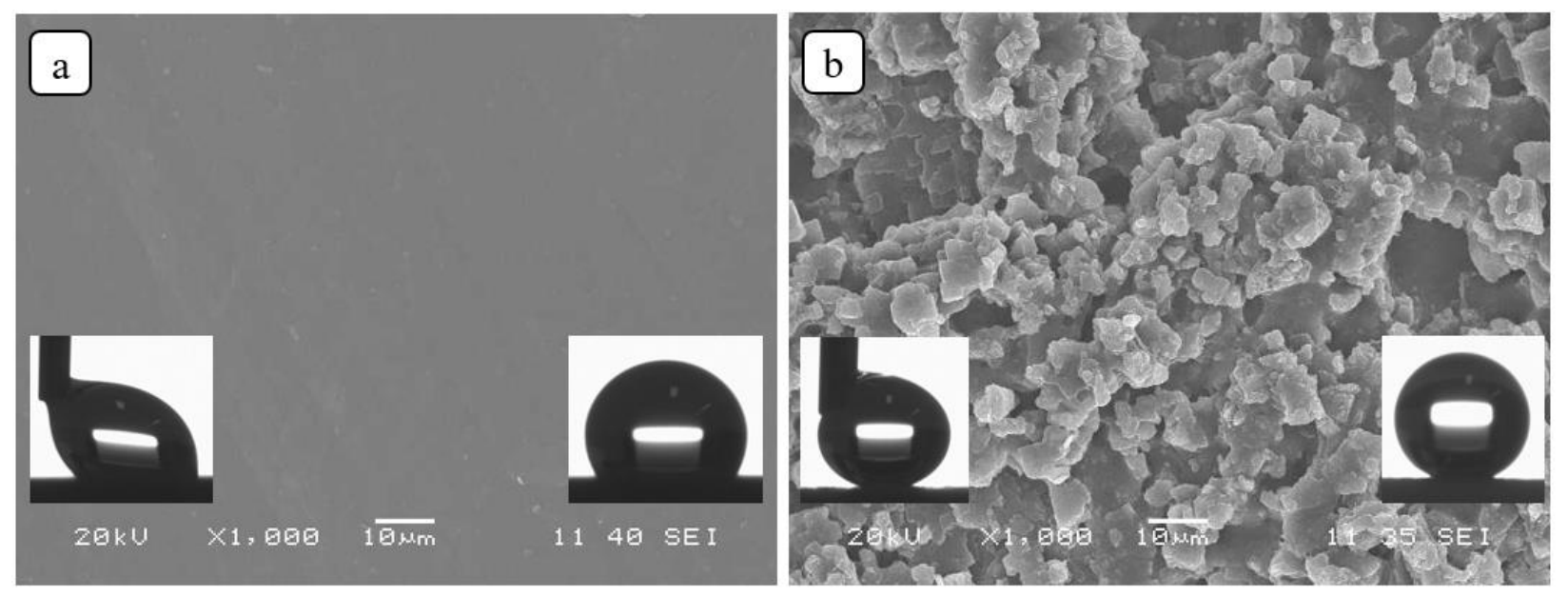

Fig. 3. SEM images of (a) pristine silicone rubber (PSR) and (b) superhydrophobic silicone rubber (SHSR) surfaces. Inset images represent the contact angle and the contact angle hysteresis images

We evaluated the roughness of the smooth, aluminum template, and superhydrophobic surfaces using a profilometry technique (Fig. 4). A $350 \times 300 \mu \mathrm{m}$ area of each surface was observed. The $\mathrm{S}_{\mathrm{q}}$ (root mean square height) of the silicone surface increased from $1.748 \mu \mathrm{m}$ to $8.124 \mu \mathrm{m}$ after the replication process. This increase in the area roughness number reflects the creation of the micro-nanostructures being responsible for its ultra-water-repellent properties. 

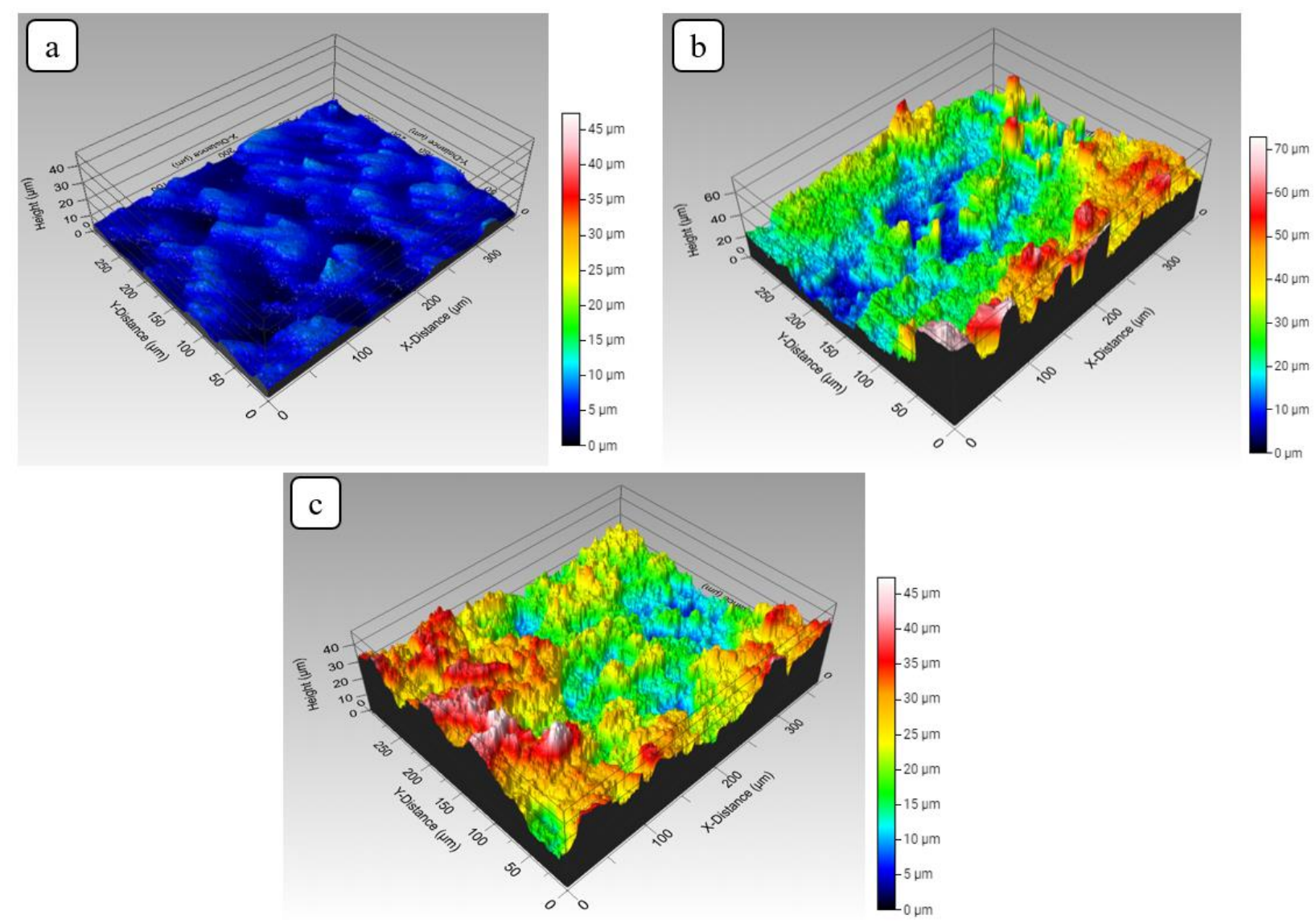

Fig. 4. 3D profiles of the (a) pristine silicone rubber surface, (b) aluminum template, and (c) superhydrophobic silicone rubber surface

The CAH values of the produced surfaces confirm that the created roughness led the surface to fall into the Cassie-Baxter state of ultra-water repellency. To confirm the superhydrophobic nature and the stability of being in the Cassie-Baxter regime, we carried out a series of tests including the droplet impacting process, the droplet evaporation measurement, the water-jet impact, the trapped air layer, and the severe droplet contact. The consecutive rebounding in the droplet impacting process can demonstrate the consistency of the Cassie-Baxter state. In the droplet evaporation measurement test, a water droplet, preserving its marblelike shape shows that it will not collapse into the structures during the evaporation process. The rebounding behavior of the water in the water-jet impact also verifies whether the transition from the Cassie-Baxter regime to Wenzel regime can take place. The trapped air layer in the surface structures can be studied by immersing the samples underwater, and a severe droplet contact with the surface can demonstrate the consistency of the Cassie-Baxter regime on the surface. Each test will be detailed in the following subsections. 


\subsection{Wettability and the Cassie-Baxter regime study}

\subsubsection{Droplet impacting process}

The process of a droplet moving on the surface is divided into four stages: the dripping stage, spreading stage, recoiling stage, and rebounding stage. ${ }^{19}$ A droplet impacting on a solid surface is a function of several factors that include impact velocity, droplet size, the properties of the liquid, surface roughness, and surface wettability. ${ }^{55}$

On both the PSR and SHSR surfaces, a maximum spreading stage in the $x$-direction (pancake shape) was observed after 6-7 ms. On the PSR surface, the water droplet receded symmetrically. At $13 \mathrm{~ms}$, a tiny jet was formed, but the droplet could not recoil or detach from the surface due to the high PSR surface energy that caused energy dissipation (Fig. 5). However, due to the hydrophobic properties of the PSR surface, the water droplet did not spread over the surface as observed on flat bare aluminum. ${ }^{55}$ A gentle up-down vibration of the droplet on the surface continued until the energy was fully dissipated and the droplet approached its final equilibrium shape at $95 \mathrm{~ms}$.

The consistency of the Cassie-Baxter regime was observed in the images of the SHSR surface (Fig. 6). The droplet impacted the SHSR surface and began to spread over the surface as the droplet's kinetic energy is converted into surface energy caused by frictional and adhesion forces. ${ }^{20}$ At $t=7 \mathrm{~ms}$, the droplet reached its extreme spreading in the $x$-direction (pancake shape). At the recoiling stage, driven by surface tension, the droplet contracted and began to rebound from the surface in the $y$-direction (15 ms, jet shape). This stage is highly dependent on the wettability of the surface. On a hydrophilic surface, the droplet remains in a flattened shape and wets the surface. On a hydrophobic surface, however, the droplet recedes and forms a jet shape. ${ }^{20}$ From $48 \mathrm{~ms}$ to $91 \mathrm{~ms}$, the droplet was in the fully rebounding stage. Various shapes for the droplet were observed at this stage, and the droplet reached its highest position at $56 \mathrm{~ms}$. From this point, the droplet fell again onto the surface, and all four stages were repeated. A total of four rebounding stages were observed, through which the maximum height of the droplet steadily decreased (3.6 mm at $56 \mathrm{~ms}, 2.2$ $\mathrm{mm}$ at $170 \mathrm{~ms}, 1.2 \mathrm{~mm}$ at $263 \mathrm{~ms}, 0.6 \mathrm{~mm}$ at $325 \mathrm{~ms}$ ). Therefore, the presence of fully rebounding stages on the SHSR surface testifies to the Cassie-Baxter regime being dominant. Fig. 7 shows schematically the influence of micro-nano air pockets of the SHSR surface in the forming of the Cassie-Baxter regime that leads to the full rebound of the impacting water droplet. 


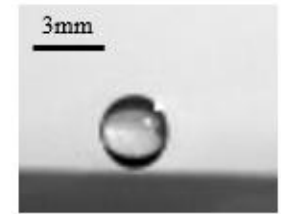

$0 \mathrm{~ms}$

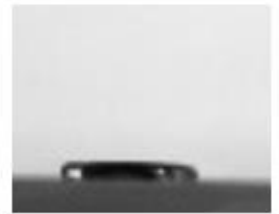

$6 \mathrm{~ms}$

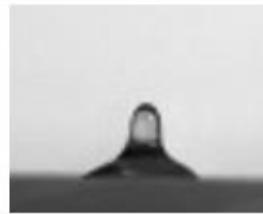

$13 \mathrm{~ms}$

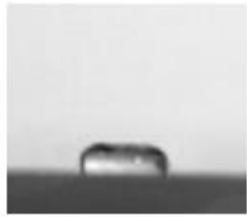

$24 \mathrm{~ms}$

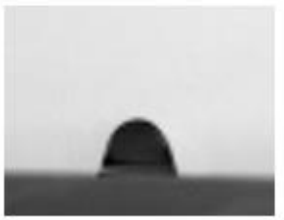

$30 \mathrm{~ms}$

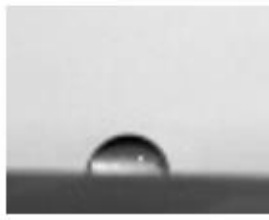

$95 \mathrm{~ms}$

Fig. 5. Sequential images of a droplet impacting onto the PSR surface

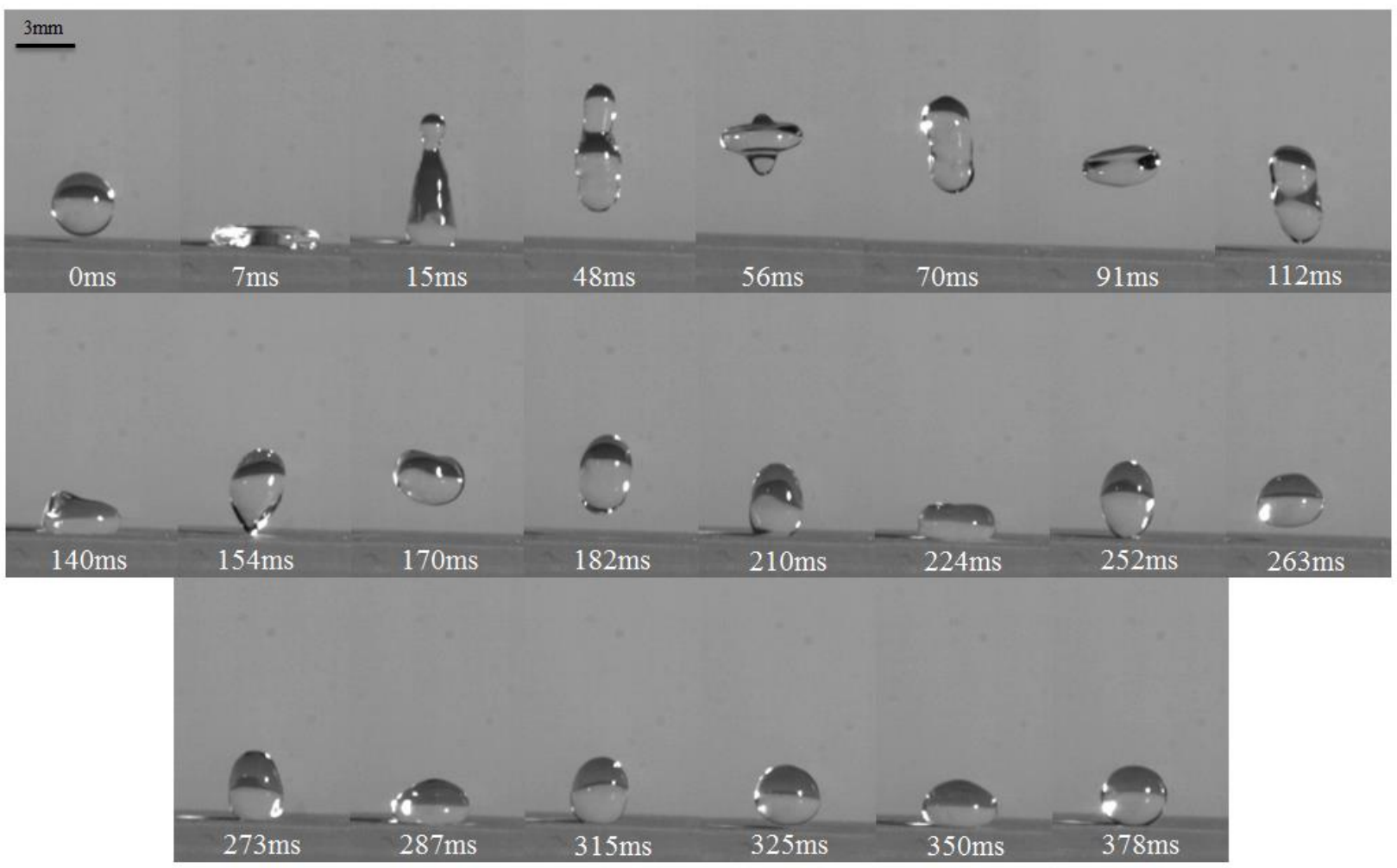

Fig. 6. Sequential images of a droplet impacting onto the SHSR surface
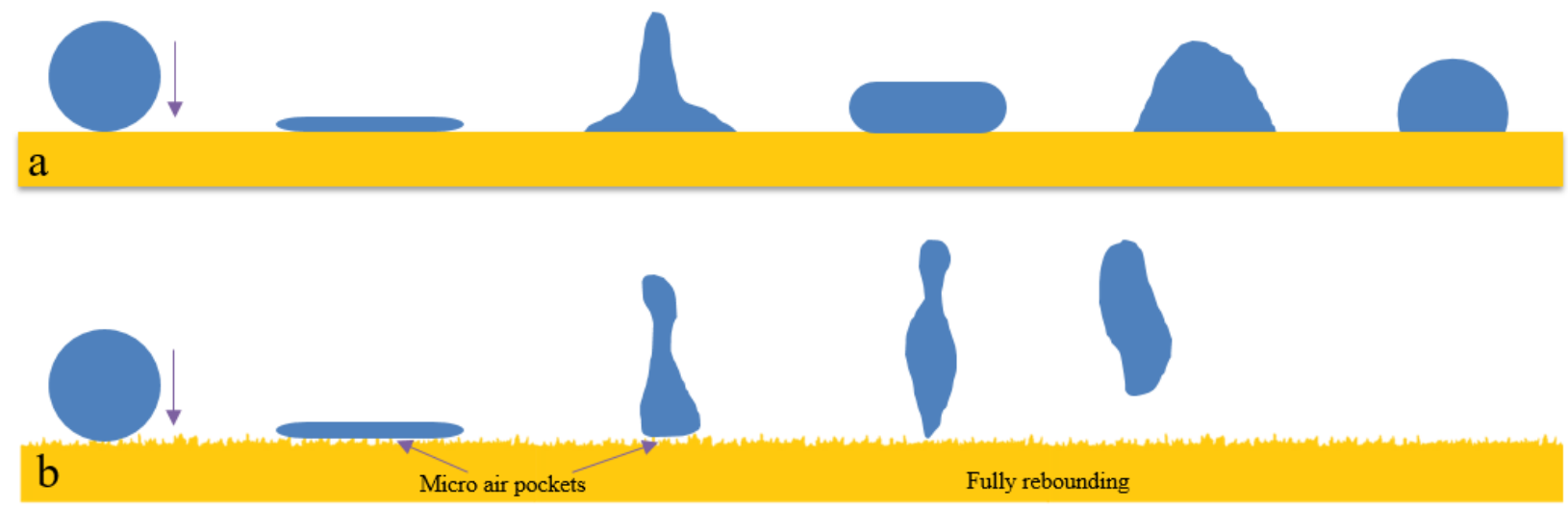

Fig. 7. Schematic diagram of a water droplet impacting on (a) smooth surface of PSR; and (b) the effect of the presence of micro-nano air pockets in producing Cassie-Baxter regime on the SHSR surface 


\subsubsection{Droplet evaporation measurements}

To study the presence of micro-nano air pockets on the produced micro-nanostructured silicone surfaces, we carried out droplet evaporation tests. A $4-\mu \mathrm{L}$ water droplet of was observed during the evaporation process, and the images were captured by the digital camera placed on a Kruss goniometer machine. The camera images were set at $8 \times$ zoom. The software (DSA1 v 1.9, Drop Shape Analysis for DSA100) calculated the contact line length and the contact area with the substrate as a function of time. ${ }^{56-58}$ Therefore, we monitored the changes in the contact line length between the droplet and the surfaces. The temperature of all experiments was identical to that of the CA tests.

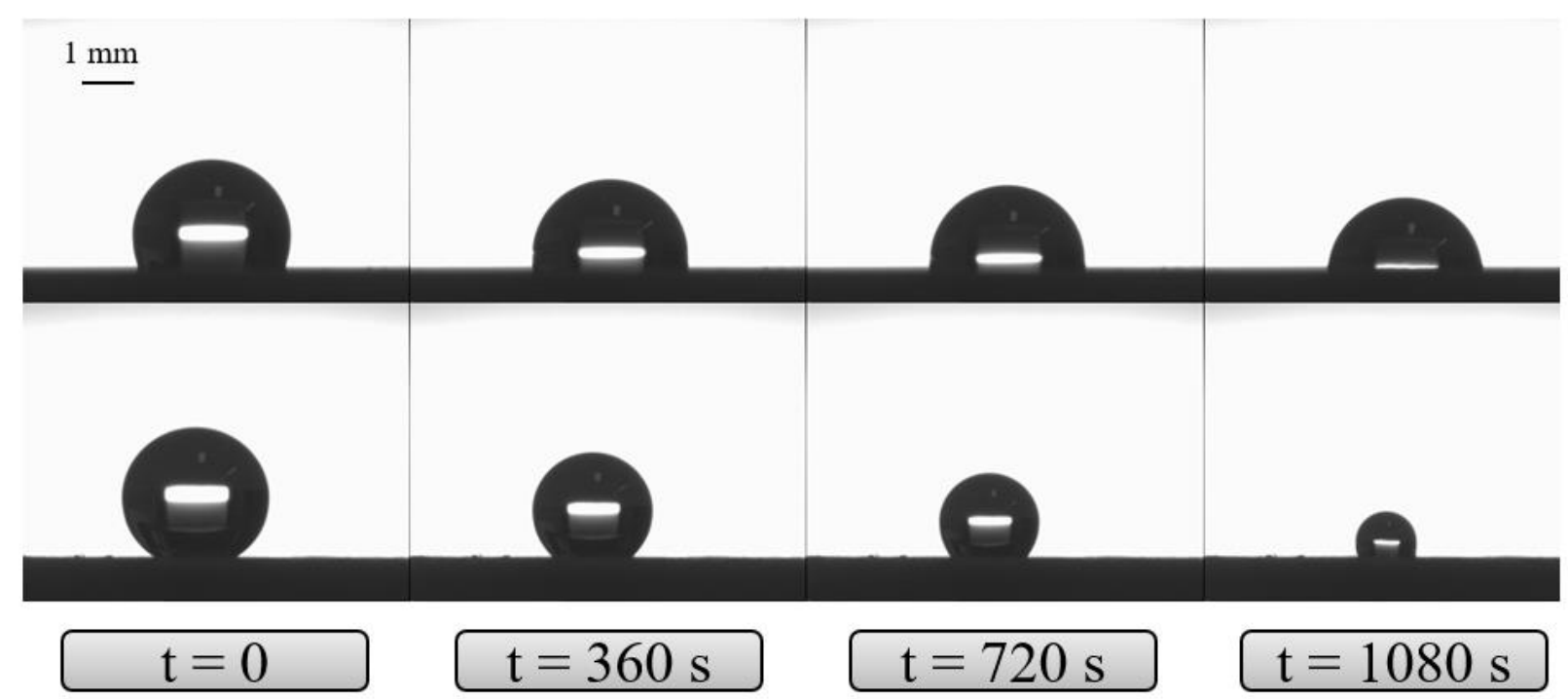

Fig. 8. The process of droplet evaporation on the pristine silicone rubber surface (upper panel) and a superhydrophobic silicone rubber surface (lower panel)

Table 1. The contact line length and water contact angle (WCA) of the superhydrophobic silicone rubber (SHSR) and pristine silicone rubber (PSR) surfaces as a function of time

\begin{tabular}{|l|l|l|l|l|l|}
\hline \multicolumn{2}{|l|}{ Time (s) } & 0 & 360 & 720 & 1080 \\
\hline Contact line length (mm) & PSR & 2.956 & 3.204 & 3.053 & 2.493 \\
\cline { 2 - 6 } & SHSR & 1.401 & 1.461 & 1.456 & 1.437 \\
\hline WCA $\left(^{\circ}\right)$ & PSR & 116.2 & 99.4 & 86.8 & 78.2 \\
\cline { 2 - 6 } & SHSR & 164.8 & 160.4 & 151.9 & 144.2 \\
\hline
\end{tabular}

On the SHSR surface, the marble-like droplet form was maintained until the latest stages of evaporation without a droplet collapse (Fig. 8). Contact line length for the PSR surface increased 8.3\% after 6 min while 
the contact line length for the SHSR surface increased only 4.2\% (Table 1). The WCA of the SHSR surface after $720 \mathrm{~s}$ remained $>150^{\circ}\left(151^{\circ}\right)$; thus, the surface continued to present superhydrophobic properties, whereas the WCA of the PSR surface after $720 \mathrm{~s}$ was $<90^{\circ}\left(86.8^{\circ}\right)$; thus, the PSR surface had lost its hydrophobicity and showed hydrophilicity (see the guidelines in Fig. 9). Moreover, the decrease in the WCA of the SHSR surface was only $7 \%$ after $720 \mathrm{~s}$, whereas the WCA of the PSR surface was reduced by about $25 \%$ after the same time. The greater adhesion of the droplet to the PSR surface caused greater evaporation from the upper part of the droplet rather than the triple liquid/solid/air line. This causes the droplet to be flattened on the surface, thereby leading to a decreased WCA for the PSR surface. However, faster evaporation was observed for the SHSR surface. The evaporation of the droplet on the SHSR surface occurred not only from the upper surface of the droplet, but also occurs at the triple line as well as the contact line between the droplet and the surface. ${ }^{59}$ The presence of micro-nanostructures facilitates the contact between the air and liquid phases even in the contact line between the water and the surface. ${ }^{22}$ Therefore, this uniform evaporation over the entire surface of the droplet led to a marble-like droplet shape on the SHSR surface until almost the last moments of the experiment. These results agree with the PSR and SHSR surface energies that were $18.78 \pm 0.5 \mathrm{mN} \cdot \mathrm{m}^{-1}$ and $0.23 \pm 0.02 \mathrm{mN} \cdot \mathrm{m}^{-1}$, respectively. The lower surface energy means more work must be expended to increase the size of the interface between the liquid and solid phases. It demonstrates that water droplets are more sphere-like on SHSR surfaces due to their low surface energy. All these observations confirm the presence of micro-nano air pockets as well as a Cassie-Baxter regime where the water droplet rests upon the micro-nano asperities and does not penetrate the surface roughness. 


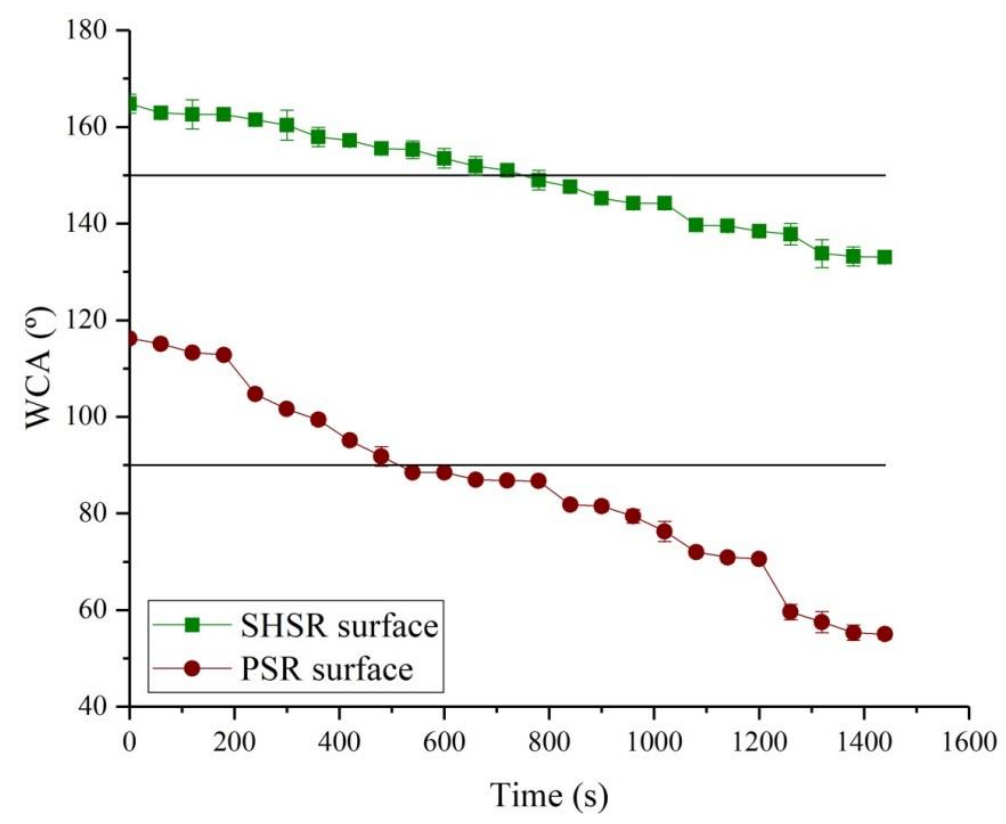

Fig. 9. Water contact angle (WCA) of the samples during the evaporation process as a function of time

\subsubsection{Water-jet impact}

We used the impact of a water jet on the fabricated surfaces to evaluate the water repelling property of the surfaces. A water jet can remove micro-nano air pockets entrapped in between the micro-nanostructures. As such, this may change the wettability character of the surface. ${ }^{26}$ As expected, the water jet adhered to the PSR upon reaching the surface. The water accumulated on the PSR surface (Fig. 10 (a)). The highspeed water jet was held on to the PSR surface due to the lack of air pockets in the intervening spaces. In the case of the SHSR surface, the water jet rebounded fully off the surface without leaving any residual water adhering to the target surface (Fig. 10 (b)). The air pockets remained intact, and the cylindrical shape of the water jet was unaltered upon rebounding from the surface. The WCA of the SHSR surface did not change even after replicate tests, thereby confirming the resistance of these micro-nano air pockets. 

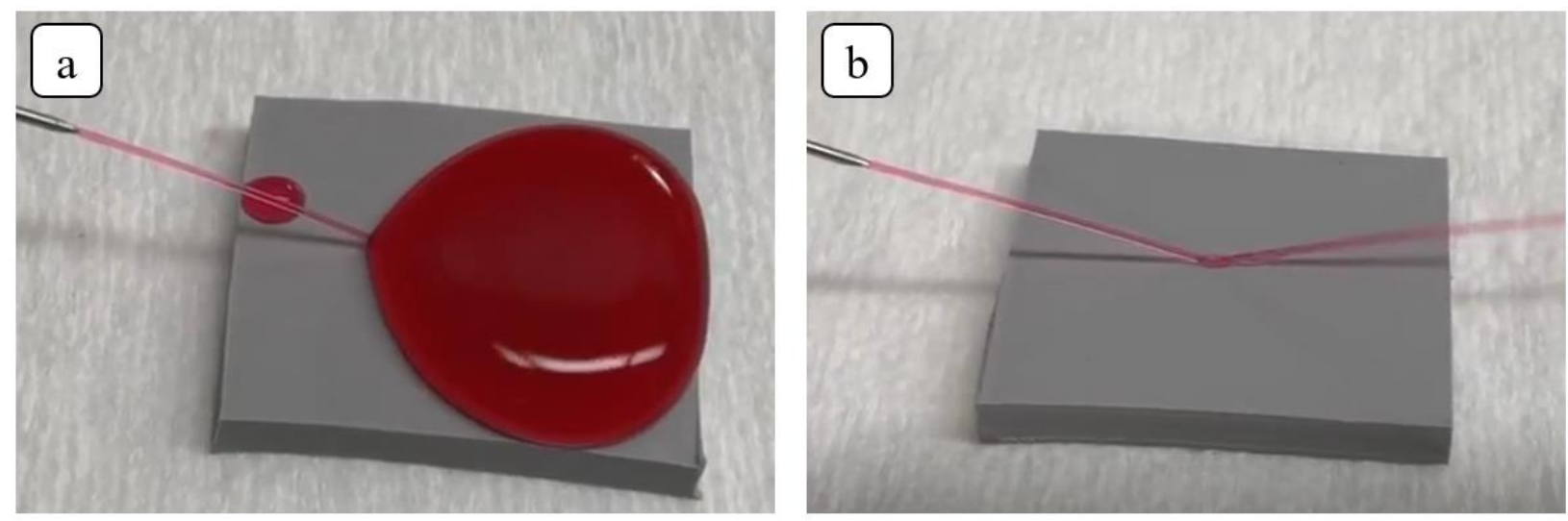

Fig. 10. Water-jet impact test on (a) pristine silicone rubber and (b) superhydrophobic silicone rubber surfaces. (The water is colored by aqueous red ink to aid observation)

\subsubsection{Trapped air layer}

Images of PSR and SHSR surfaces underwater show that the bright plastron layer is obvious on the SHSR surface (Fig. 11). This is due to the total reflectance of light at the air layer that is trapped in between the SHSR surface micro-nanostructures. ${ }^{31}$ This phenomenon did not occur on the PSR surface due to the complete contact of the water with the PSR surface interstices. This property is highly important in reducing drag or friction of a superhydrophobic surface. ${ }^{32}$

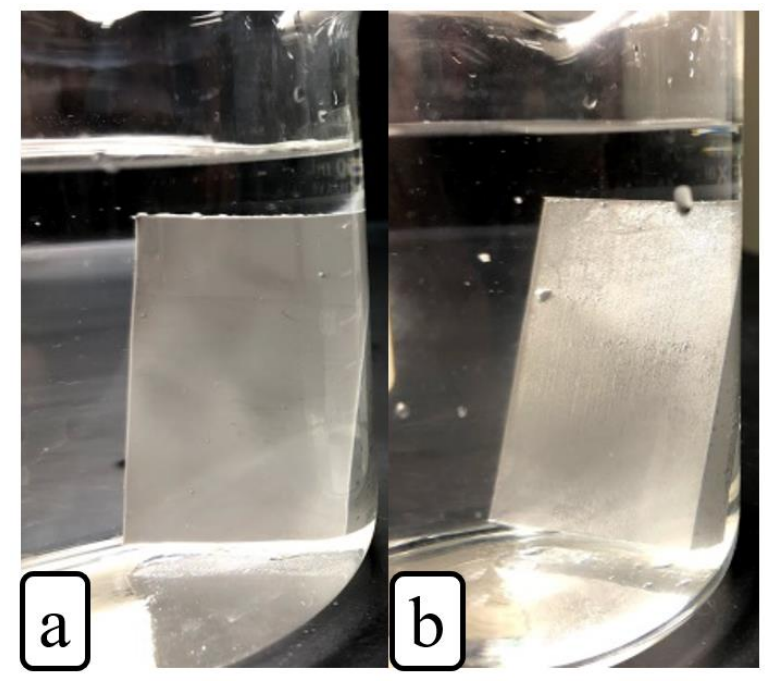

Fig. 11. (a) Pristine silicone rubber and (b) superhydrophobic silicone rubber surfaces underwater

\subsubsection{Severe droplet contact}

Using the severe water droplet contact with the surface test, we assessed the stability of the Cassie-Baxter regime (Fig. 12). A 4- $\mu \mathrm{L}$ water droplet adhering to a needle was brought to the surfaces. After the initial contact between the droplet and the surface (which is a representative of the surface WCA), the droplet was 
pushed toward the surface using the needle. The droplet was then lifted upward. Due to the ultra-water repellency property of the SHSR surface, the droplet detached easily and rapidly from the surface without leaving any traces of water. This ascertains the stability of the Cassie-Baxter regime when additional forces are applied. ${ }^{30}$

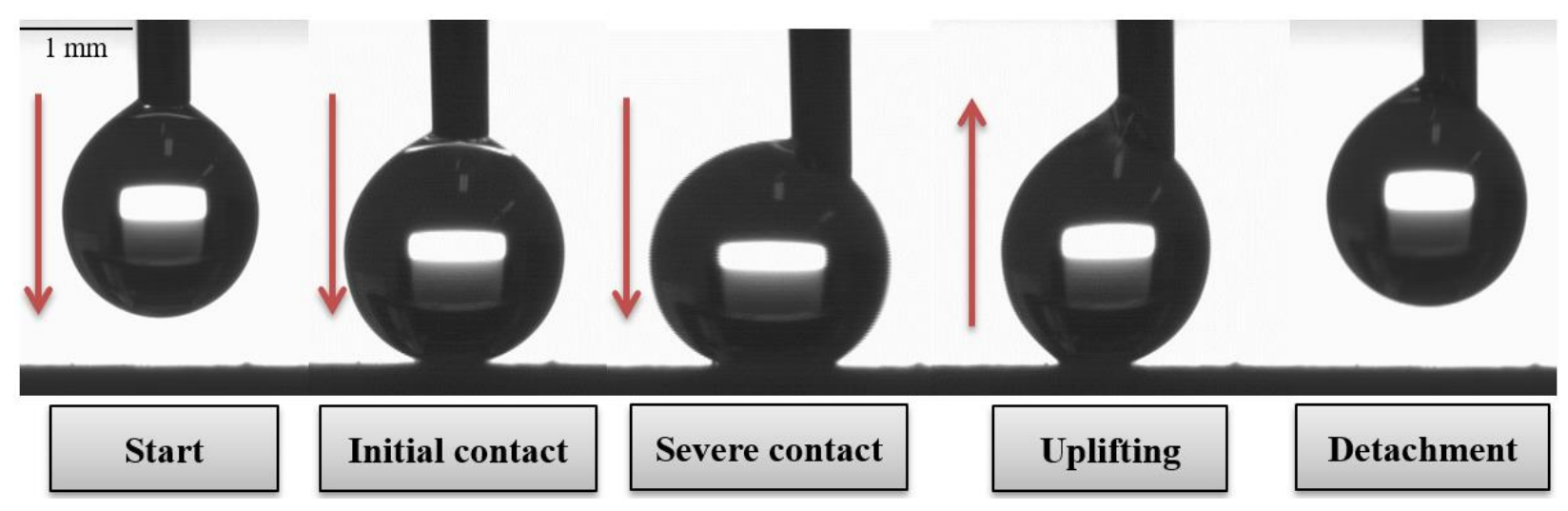

Fig. 12. Sequential images showing the severe droplet contact with the superhydrophobic silicone rubber surface

\subsection{Self-cleaning property}

To study the self-cleaning properties of the produced SHSR surfaces, we divided the test conditions into two categories: non-dissolved and dissolved contamination. The latter was again divided into a wet subcategory where the contaminant solution was not allowed to dry on the surface, and a dry subcategory where the contaminant solution dried and sediment remaining on the surface was then cleaned off. The nondissolved contamination test includes the sweeping and collection of contaminant particles by a water droplet. The wet dissolved contamination test includes a dropwise contaminated solution. The dry dissolved contamination tests include dropwise contaminant solution, immersion, and spraying.

The dry dissolved contamination tests that involve drying and sedimentation processes imitated outdoor conditions where solutions of contaminants are deposited onto the surface and then dry out and adhere to the surface, thereby rendering the cleaning of the surfaces more difficult.

\subsubsection{Non-dissolved contamination tests}

\subsubsection{1. $\quad$ Sweeping and collection by a water droplet}

In this first test, we compared the adhesion between the water droplet and pollution particles with the adhesion between pollution particles and the superhydrophobic surface. Kaolin powder was scattered homogeneously on the silicone surface using a 60 mesh. The kaolin contaminant was set onto the surface for $30 \mathrm{~min}$ before carrying out the next step. A water droplet, still fixed to the syringe needle, swept the contaminant off the surface. Following the passage of the droplet, no trace of contaminants remained along 
the droplet path on the SHSR surface. Thus, the CAH of the SHSR surface was low enough to allow the water droplet to move easily over the surface while remaining stuck to the syringe needle. Furthermore, it demonstrated the self-cleaning property of the surface as the contaminants adhered to the water droplet rather than the SHSR surface. A single water droplet cleaned almost an entire $22 \mathrm{~mm} \times 17 \mathrm{~mm}$ surface (Fig. 13). When we performed the same experiment on the PSR surface, we observed that the water droplet stuck to the polluted surface as soon as it contacted the surface.

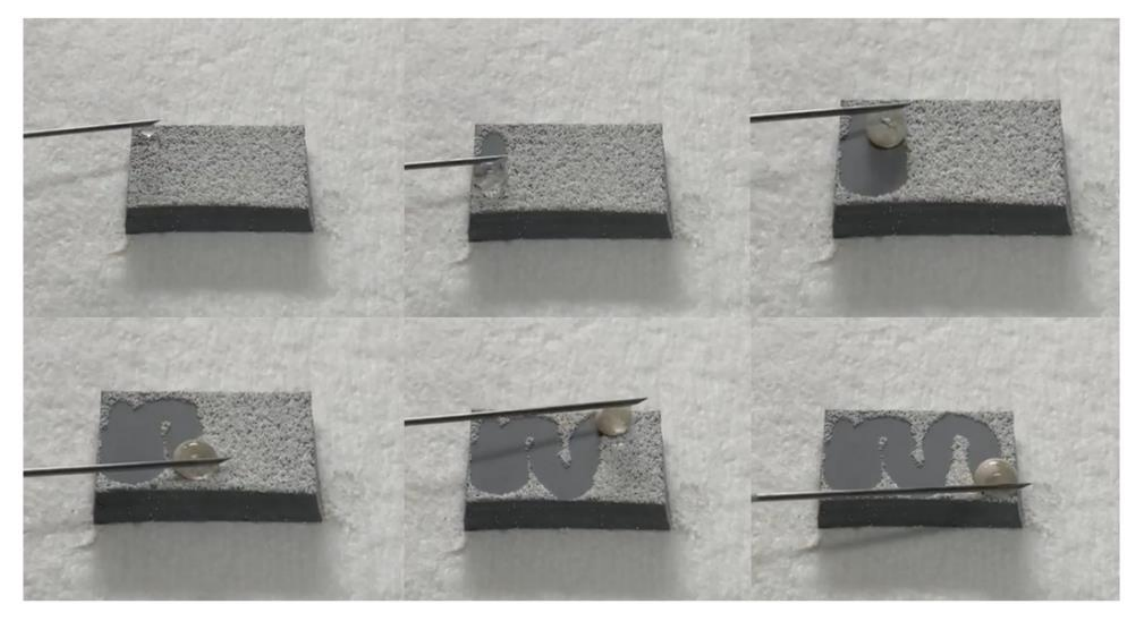

Fig. 13. Self-cleaning of the silicone surface by water droplet sweeping

As contaminant particles are hydrophilic and the surface is superhydrophobic, the particles adhere very strongly to the water droplet (Fig. 14). In contrast to being transparent at the onset of the test, the opaque appearance of the water droplet at the end of the process relates to the collected contaminants by the water droplet.
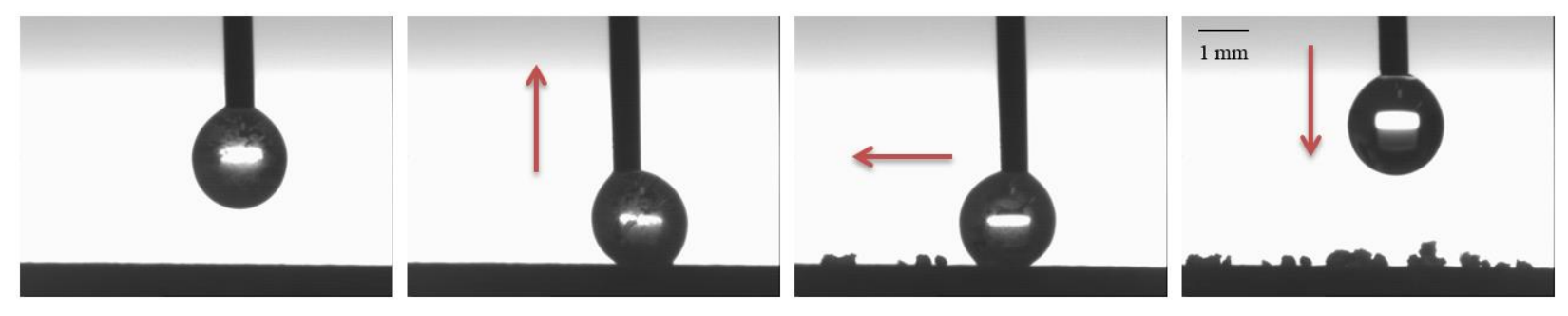

Fig. 14. Sequential images of the collecting process of the contaminant by a rolling water droplet along the surface (right to left)

\subsubsection{Wet dissolved contamination tests}

\subsubsection{Dropwise contaminant solution}

Using the prepared $40 \mathrm{~g} \cdot \mathrm{L}^{-1}$ multi-contaminant solution, we evaluated the self-cleaning property of the SHSR on a $3^{\circ}$-tilted surface - the chosen angle is similar to the inclination of an electrical insulator shed. We used a syringe needle to place the solution onto the surfaces in a continuous manner from $\mathrm{ca} .3 \mathrm{~cm}$ 
above the surface (Fig. 15). The PSR surface retained many of the droplets, whereas the SHSR surface, as expected, repelled the droplets and remained thoroughly clean. Fig. 15 (a) sequentially shows the accumulated dirty solution on the PSR surface and Fig. 15 (b) presents in sequence the self-cleaning behavior of the produced SHSR. The SHSR surface repels the dirty solution droplets in a similar manner as with pure water droplets. The dirty droplets roll off the surface immediately upon landing on the surface. The removed dirty solution can be clearly seen on the underlying paper towel.
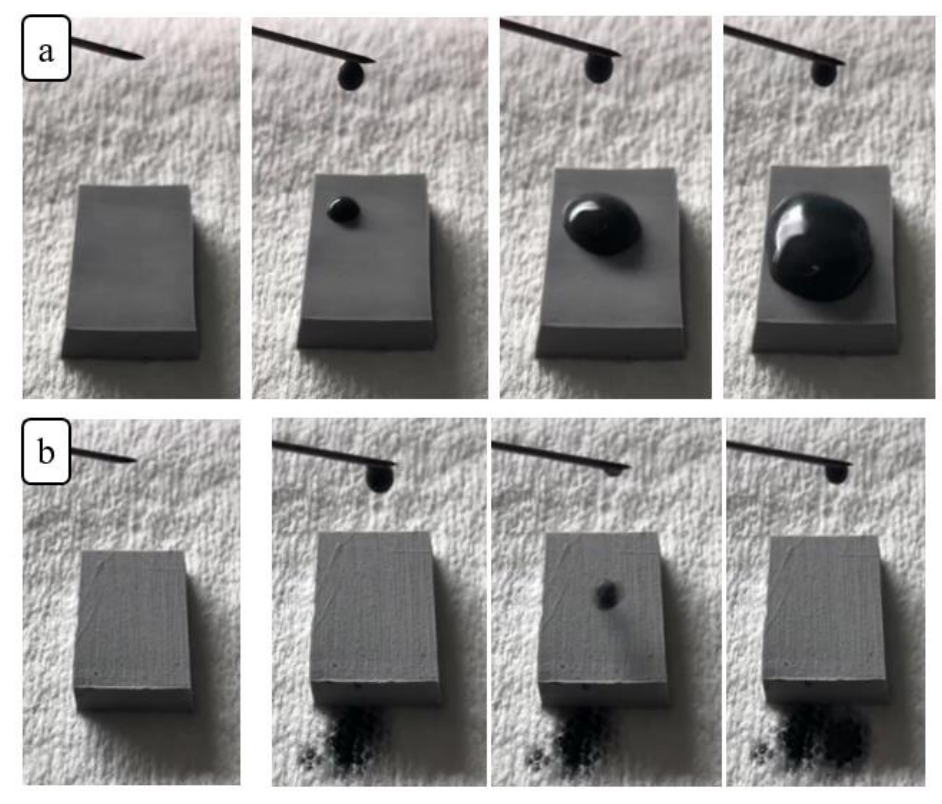
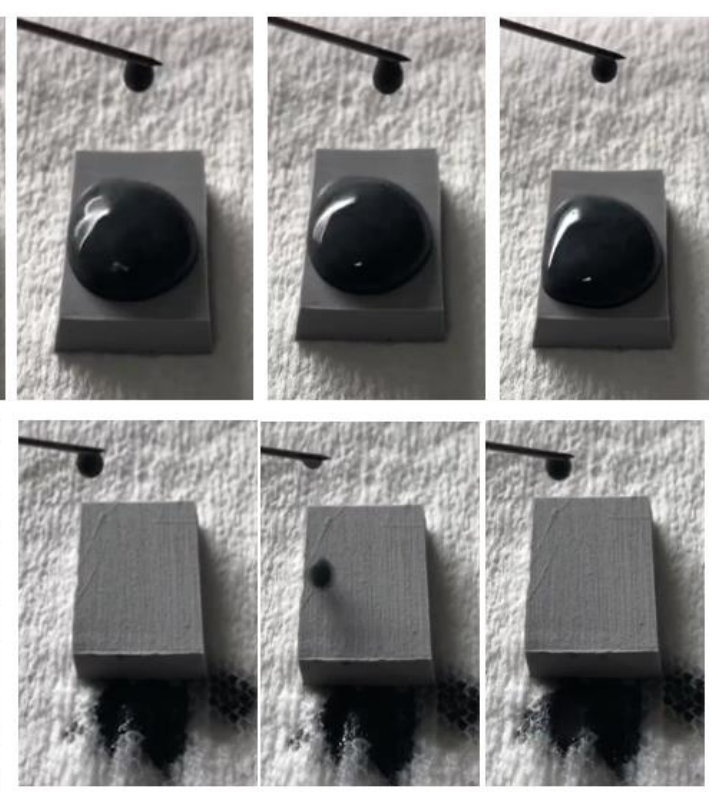

Fig. 15. Sequential representation of (a) the accumulation of dirty solution on the pristine silicone rubber surface and (b) the self-cleaning behavior of the produced superhydrophobic silicone rubber surface after wet dissolved contamination

\subsubsection{Dry dissolved contamination tests}

\subsubsection{Dropwise contaminant solution}

In the first test of dried, dissolved contamination tests, we examined the self-cleaning ability of the surface through the cleaning of two dried droplets of a kaolin solution on the prepared surfaces. We prepared a 40 $\mathrm{g} \cdot \mathrm{L}^{-1}$ kaolin solution (regarding IEC standard 60507 ${ }^{48}$ ) and thoroughly mixed the water-kaolin solution. Before any sedimentation could occur, we gently placed two droplets onto each surface using a syringe (Fig. $16(a, b)$ ). The surfaces were then dried at ambient temperature for $4 \mathrm{~h}$ to evaporate all water and have the kaolin sediment onto the surfaces (Fig. $16(\mathrm{c}, \mathrm{d})$ ). It must be noted that a completely flat trace remained on the PSR surface after drying (Fig. 16 (c)); however, due to the ultra-water repellency of the SHSR surface, the shape of the dried kaolin solution was spherical even after drying (Fig. 16 (d)), retaining its initial shape. We then assessed the self-cleaning performance of the surfaces placed on a completely flat holding plate by removing the dried kaolin stains using water droplets. All added water $(\sim 0.4 \mathrm{~mL})$ to the PSR surface accumulated on the surface, and the dried kaolin stains remained fixed on the surface (Fig. 16 
(e)). In contrast, two water droplets $(40 \mu \mathrm{L})$ were sufficient to remove completely the kaolin spots from the SHSR surface. The removed kaolin spots are obvious on the base plate (Fig. 16 (f)), and no trace is detectable on the SHSR surface.
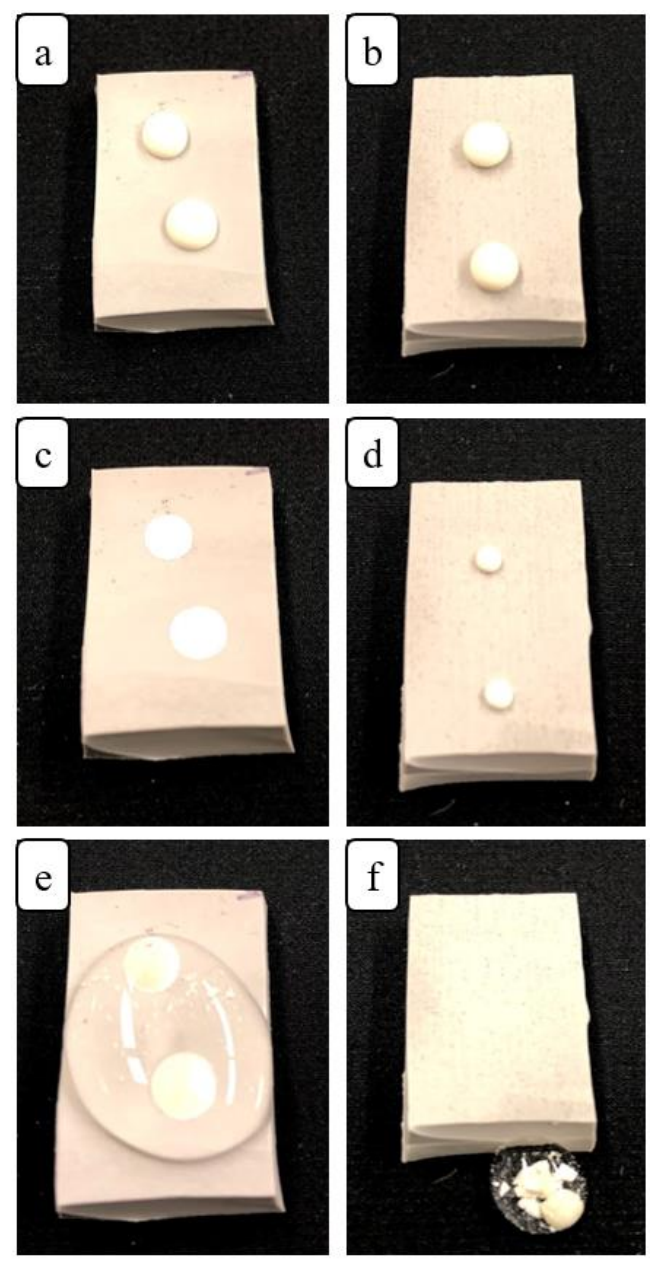

Fig. 16. Placement of two kaolin solution droplets on the (a) pristine silicone rubber (PSR) and (b) superhydrophobic silicone rubber (SHSR) surfaces; droplets dried at ambient temperature for $4 \mathrm{~h}$ to produce (c) thoroughly flat traces on the PSR and (d) marble-like droplets on the SHSR surfaces; cleaning the dried droplets of kaolin solution off the (e) PSR and (f) SHSR surfaces

We also repeated the same test to compare the self-cleaning ability of the surfaces on a $3^{\circ}$-tilted holding plate (inspired by the electrical insulators' shed inclination). This time, although some contaminant was removed from the PSR surface, the dried kaolin stain remained fixed on the surface even after rinsing with $\sim 10 \mathrm{~mL}$ of water for nearly $7 \mathrm{~s}$. Comparing the initial weights and after-rinsing weights of the surfaces, we calculated that $\sim 79 \%$ of the contaminant mass remained on the PSR surface. In contrast, the SHSR surface exposed to the same conditions self-cleaned easily, and we detected no weight increase (Table 2). 
Table 2. The weight of PSR and SHSR surfaces before applying the kaolin contaminant and after rinsing the surfaces

\begin{tabular}{|l|l|l|l|l|}
\hline Sample & Initial weight $(\mathrm{g})$ & $\begin{array}{l}\text { Weight after } \\
\text { sedimentation } \\
\text { rinsing }(\mathrm{g})\end{array}$ & $\begin{array}{l}\text { Weight after } \\
\text { Accumulated } \\
\text { contamination on the } \\
\text { surface }\end{array}$ \\
\hline PSR & $2.801 \pm 0.002$ & $2.891 \pm 0.002$ & $2.872 \pm 0.003$ & $\sim 79 \%$ \\
\hline SHSR & $3.613 \pm 0.001$ & $3.703 \pm 0.002$ & $3.613 \pm 0.002$ & $\sim 0 \%$ \\
\hline
\end{tabular}

When we compared the optical microscopic images of the SHSR and PSR surfaces prior to application of the kaolin solution and following the rinsing of the surfaces by water droplets (Fig. 17), no contamination residue was observed on the SHSR surface (Fig. 17 (c)), whereas much of the PSR surface remained covered by the contaminant (Fig. 17 (d)).

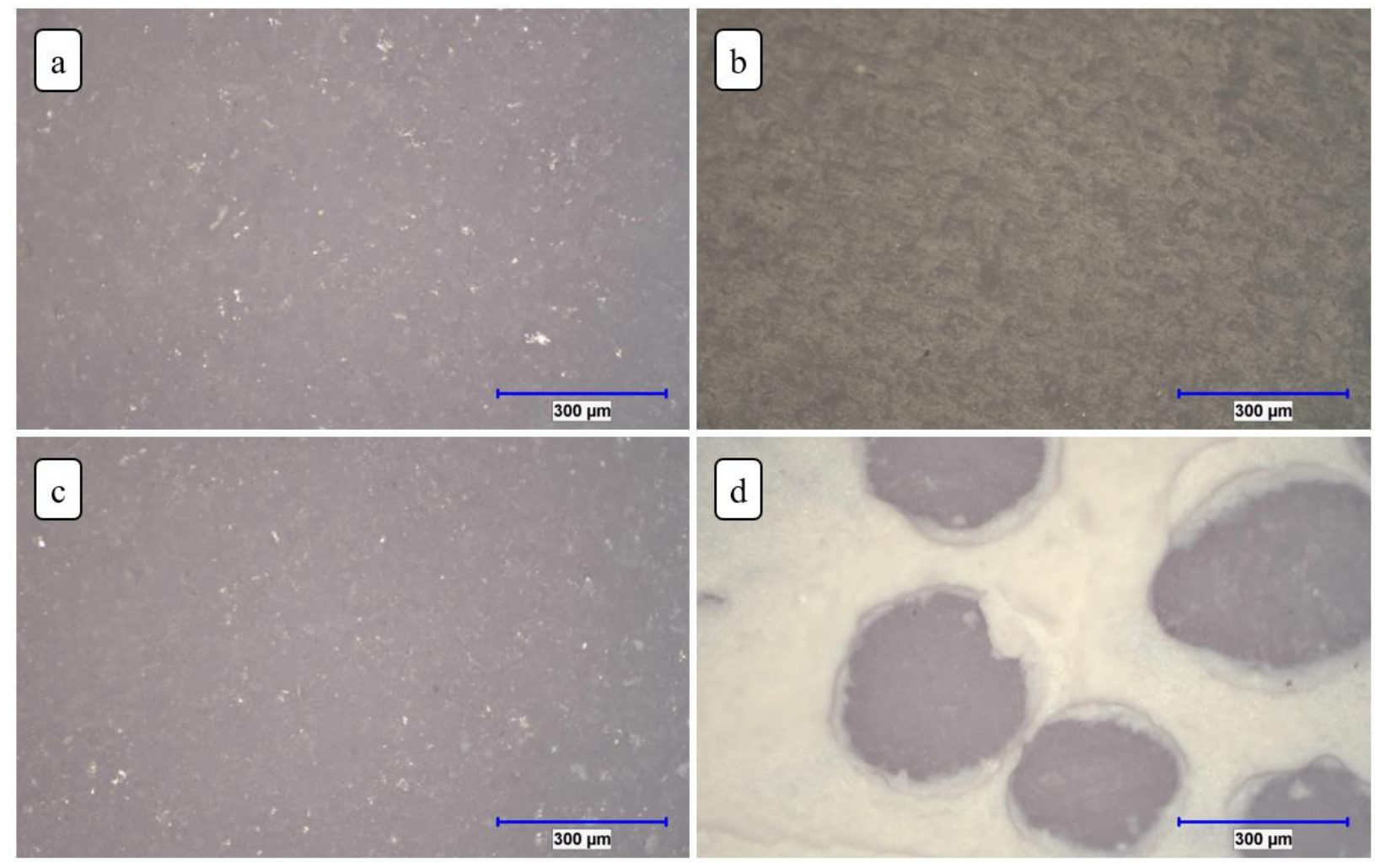

Fig. 17. Optical microscope images of the (a) superhydrophobic silicone rubber (SHSR) and (b) pristine silicone rubber (PSR) surfaces before applying droplets of kaolin solution and images of the (c) SHSR and (d) PSR surfaces after rinsing of the surfaces

Our FTIR spectra results for SHSR and the PSR surfaces illustrated no difference between the FTIR spectra of the SHSR and PSR surfaces. In addition, the self-cleaning property of the produced superhydrophobic surface left no trace of contaminants on the surface (Fig. 18). Changes in FTIR spectra of the PSR surface 
is attributed to the amount of the kaolin pollution that remained on the surface post-rinsing (Fig. 18). Kaolin consists mainly of $\mathrm{SiO}_{2}, \mathrm{Al}_{2} \mathrm{O}_{3}$, and $\mathrm{H}_{2} \mathrm{O}\left(48.12,36.33\right.$ and 4.77 wt.\%, respectively). ${ }^{60}$ Due to the $\mathrm{SiO}_{2}$ of the kaolin, we observe a peak corresponding to Si-O stretching at $1000-1030 \mathrm{~cm}^{-1}$ on the FTIR spectra. However, peaks around approximately $805-855 \mathrm{~cm}^{-1}$ and $1245-1275 \mathrm{~cm}^{-1}$, which are related to $\mathrm{Si}\left(\mathrm{CH}_{3}\right)_{2}$ and $\mathrm{Si}\left(\mathrm{CH}_{3}\right)$, respectively, had almost vanished as the silicone rubber surface was covered by the kaolin contamination. The new peaks at $3620-3654 \mathrm{~cm}^{-1}$ were characteristic of $\mathrm{OH}$ stretching of the inner surface hydroxyl groups. Moreover, the sharp band at around $912 \mathrm{~cm}^{-1}$ and the weak shoulder at $940 \mathrm{~cm}^{-1}$ were due to the $\mathrm{OH}$ deformation of inner hydroxyl groups and $\mathrm{Al}(\mathrm{VI})-\mathrm{OH}$ vibrations. ${ }^{61}$

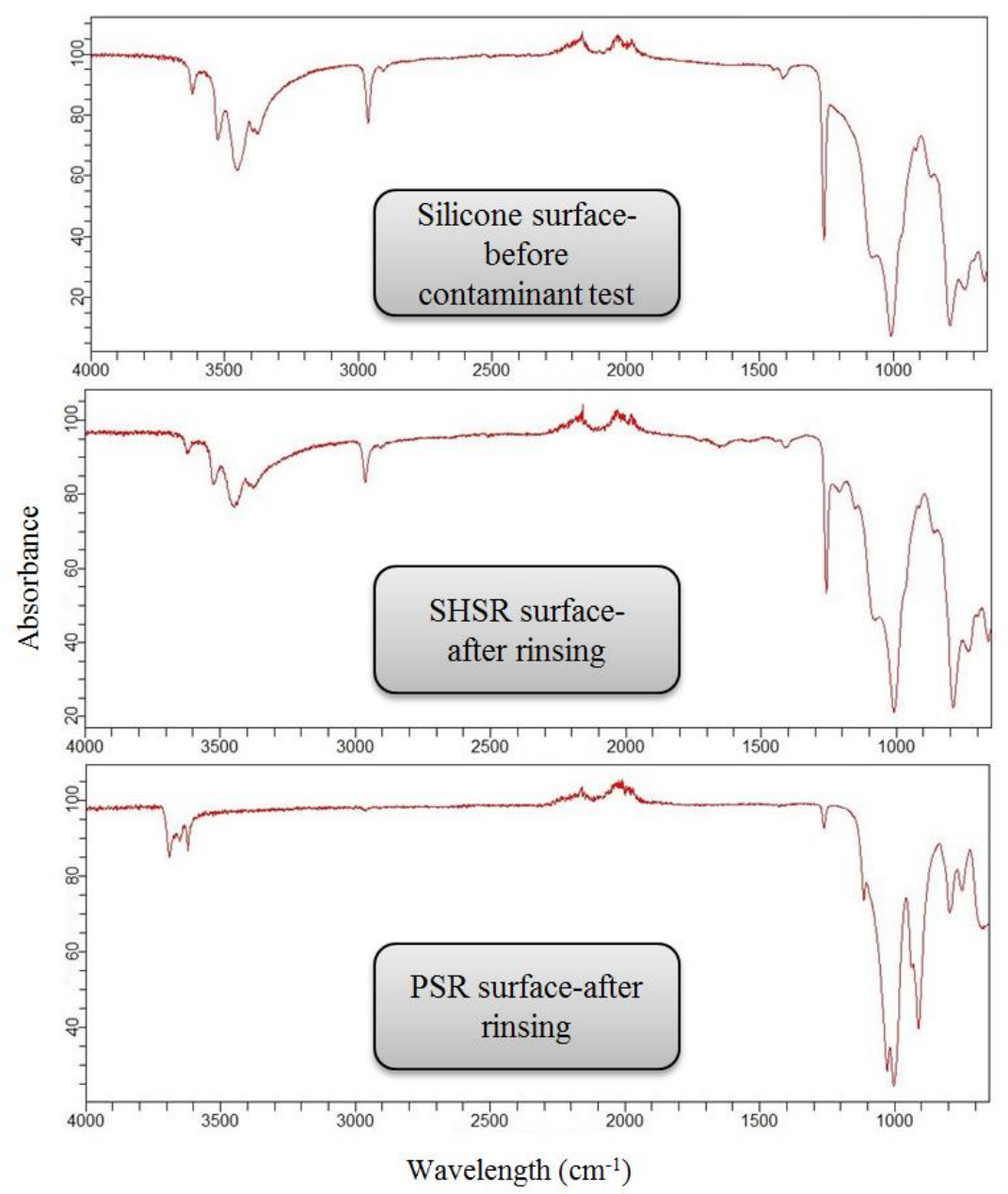

Fig. 18. FTIR spectra of the silicone surface before the application of the kaolin contaminant and after the rinsing of the two superhydrophobic silicone rubber (SHSR) and pristine silicone rubber (PSR) surfaces

\subsubsection{Immersion in the contaminant solution}

The multi-contaminant solution (i.e., $40 \mathrm{~g} \cdot \mathrm{L}^{-1}$ dirty solution consisting of $\mathrm{SiO}_{2}$ particles, carbon black, salt, and kaolin in water) was used for the immersing in the contaminant solution test as the second test for the dry dissolved contamination. The PSR and SHSR surfaces (Fig. 19 (a)) were completely immersed in the 
dirty solution (Fig. 19 (b)) and were then placed on a hot plate at $70^{\circ} \mathrm{C}$ for $2 \mathrm{~h}$ to evaporate the water from the dirty solution to dry and fix the sediment onto the surfaces (Fig. 19 (c)). Following this application and the drying of the contaminant solution, much sediment had accumulated on the PSR surface, whereas the SHSR surface remained clean (Fig. 19 (d)). Using water droplets, we then attempted to remove the accumulated contaminants from the PSR surface. We used $\sim 10 \mathrm{~mL}$ water to clean the PSR surface. The surface of the paper towel surrounding the PSR surface was covered by a portion of the surface contaminants, whereas most of the contaminants adhered strongly to the PSR, and droplets also accumulated on the surface (Fig. 19 (e)). Thus, the adhered contaminants to the PSR surface converted the surface into a hydrophilic surface (WCA of $\sim 63^{\circ}$ ), whereas the SHSR retained its superhydrophobicity under such severe contamination, i.e., no change of WCA was observed.
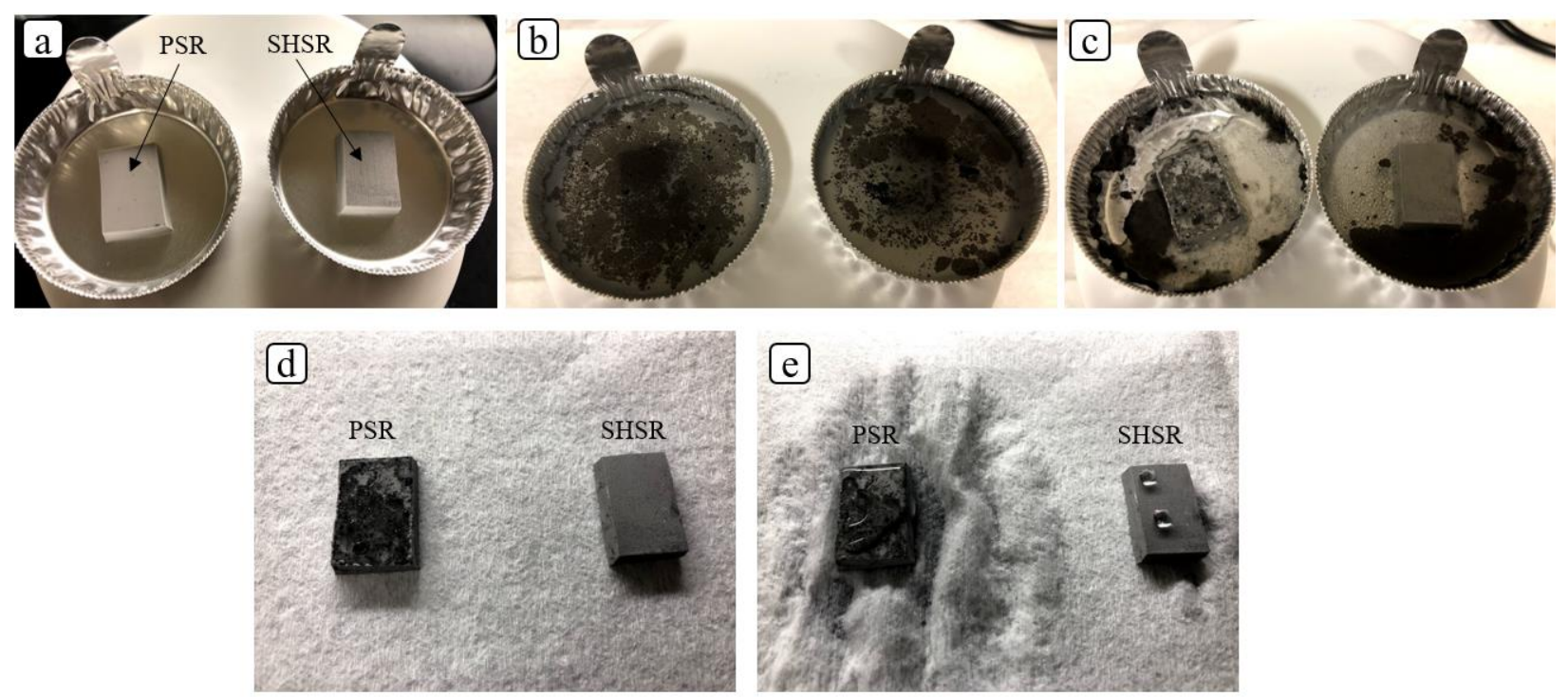

Fig. 19. (a) Placement, (b) immersion, (c) drying, (d) removing, and (e) cleaning steps of pristine silicone rubber (PSR) and superhydrophobic silicone rubber (SHSR) surfaces

\subsubsection{3. $\quad$ Spraying of the contaminant solution}

In the third test, we imitated rainy outdoor conditions in an area marked by air pollution where rainwater dissolves the atmospheric contaminants. The contaminated rain falls on the surfaces, and after rain stops, the dirty solution on the surfaces gradually dries. Thus, there is a chance for the dirty surfaces to be cleaned off by the next rainfall, although not all contaminants may be removed. Due to this deposition-dryingdeposition cycle and possible lack of complete removal of the contaminants by the subsequent rainfall, this scenario (or test) is considered as the most severe. This test provides a very realistic scenario to compare the functionality of the produced SHSR surface with the PSR surface.

The kaolin solution (40 g. $\mathrm{L}^{-1}$ based on the IEC standard ${ }^{48}$ ) was sprayed onto the surfaces, dried at ambient temperature, and then cleaned off the surfaces by spraying deionized water. We used 15 bar air pressure 
spray to apply $100 \mathrm{~mL}$ of kaolin solution onto both SHSR and PSR surfaces (Fig. 20 (a, b)). The surfaces were attached in a vertical position onto a base. After spraying, the samples were dried at ambient temperature for $15 \mathrm{~min}$ to let the contaminant adhere to the surface (Fig. 20 (c, d)). We then washed the surfaces using $50 \mathrm{~mL}$ of deionized water using the same air pressure spray (Fig. $20(\mathrm{e}, \mathrm{f})$ ). We repeated this cycle five times. The appearance of the surfaces after the five spraying, drying, and washing cycles is shown in Fig. $20(g, h),(i, j)$, and $(k, 1)$, respectively. We then let the surfaces rest for $1 \mathrm{~h}$ (Fig. 20 (m, n)) and measured the surface WCA and CAH. The hydrophobic property of the PSR surface deteriorated and produced a WCA of $77^{\circ} \pm 3^{\circ}$ and a CAH of $54^{\circ} \pm 2^{\circ}$ after five cycles. This is due to the stiction of the hydrophilic contaminants to the PSR surface rendering the surface hydrophilic. However, the SHSR retained a WCA of $150.1^{\circ} \pm 1.9^{\circ}$ and a CAH of $16^{\circ} \pm 2^{\circ}$ even after the five cycles.
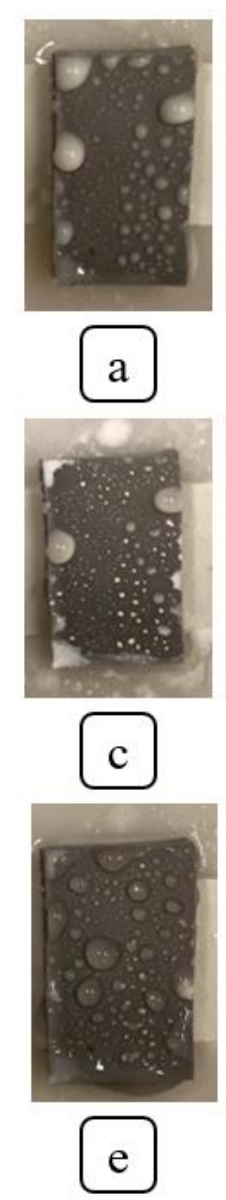
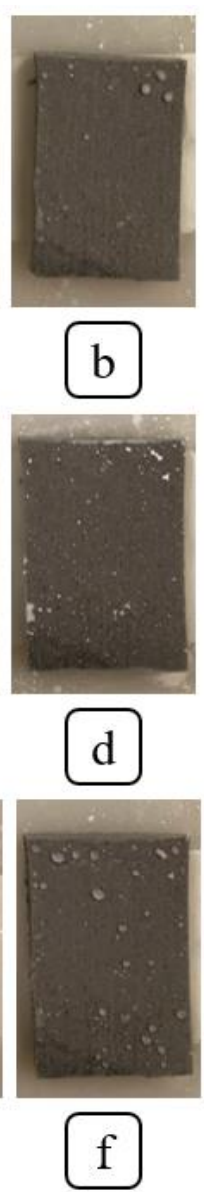
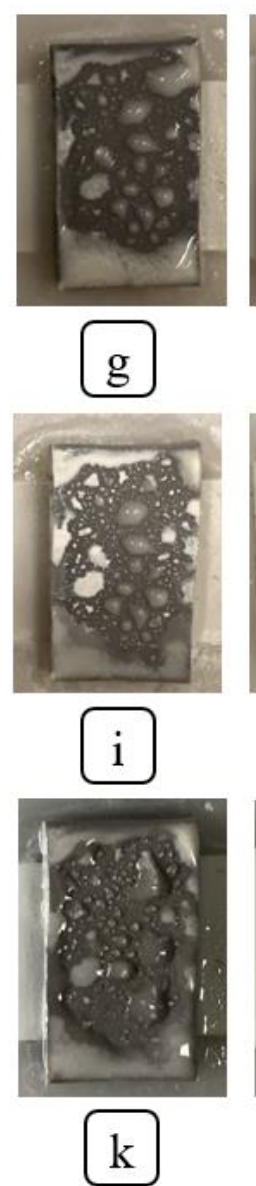

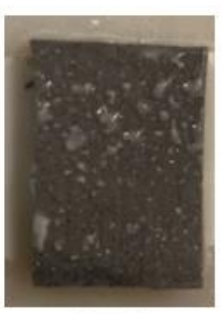

$\mathrm{h}$
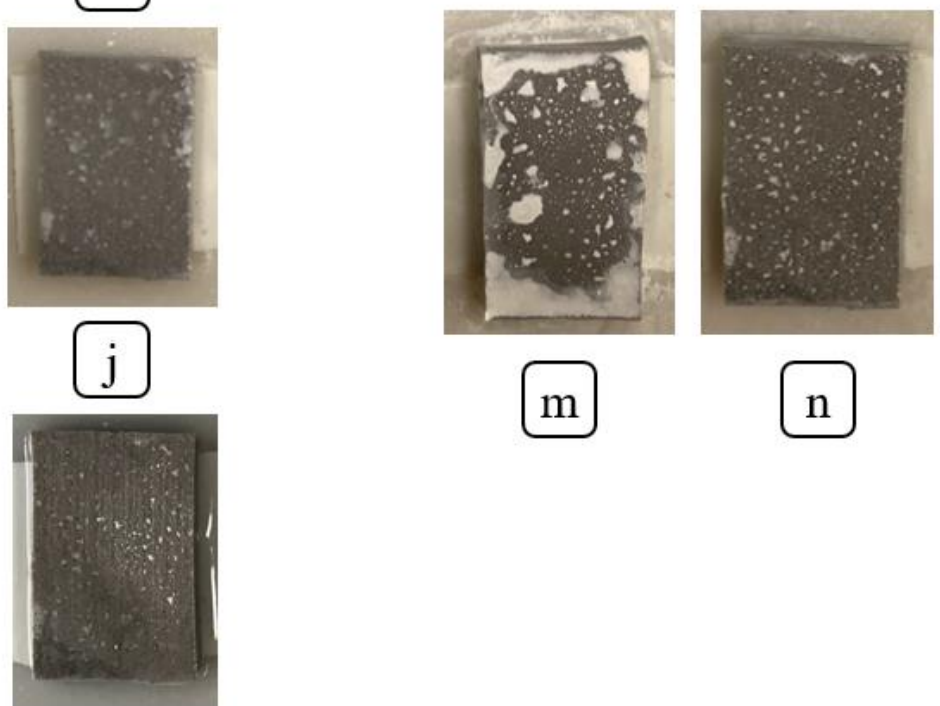

$\mathrm{n}$

Fig. 20. Images captured after the initial (a) spraying, (c) drying, (e) washing cycle of pristine surface and for the superhydrophobic surface (b-d-f); after the fifth (g) spraying, (i) drying, (k) washing cycle of PSR and SHSR surfaces (hj-l); Final appearance of the (m) PSR and (n) SHSR surfaces

Following the spraying test, we used optical microscopic images of the SHSR and PSR surfaces to compare the amount and size of adhered contaminants to each surface (Fig. 21). The edges of the PSR surface are 
obvious in Fig. 20 (m) as the surface is completely covered by contaminants (Fig. 21 (a)). This severe accumulation of contaminants on the edges of PSR can lead to a functional failure after multiple contamination-drying cycles. The edges and the middle of the SHSR surface indicated an insignificant difference in contaminant accumulation (Fig. 21 (b, d)). The largest accumulations in the middle of SHSR surface were $85 \mu \mathrm{m}$ in diameter, while spots $300-500 \mu \mathrm{m}$ in diameter were found in the middle of PSR surface (Fig. 21 (c, d)). Thus, even though the sprayed contaminant particles could adhere to the SHSR surface and accumulate in some spots, the surface could still preserve its WCA of $>150^{\circ}$. This is especially important when noting that the PSR lost its hydrophobicity after a significant amount of contaminants had accumulated on its surface. Weighing the samples before and after the spraying test indicated a $1.96 \%$ increase in weight for the PSR surface and a $0.1 \%$ increase in weight for the SHSR surface. This marked difference in accumulated contaminants on the two surfaces (i.e., SHSR surface accumulated ca. 19 times less contamination than the PSR surface) testified to the self-cleaning properties of the SHSR surface during the test, as the SHSR surface could repel the contaminant solution and also self-clean when sprayed with water.
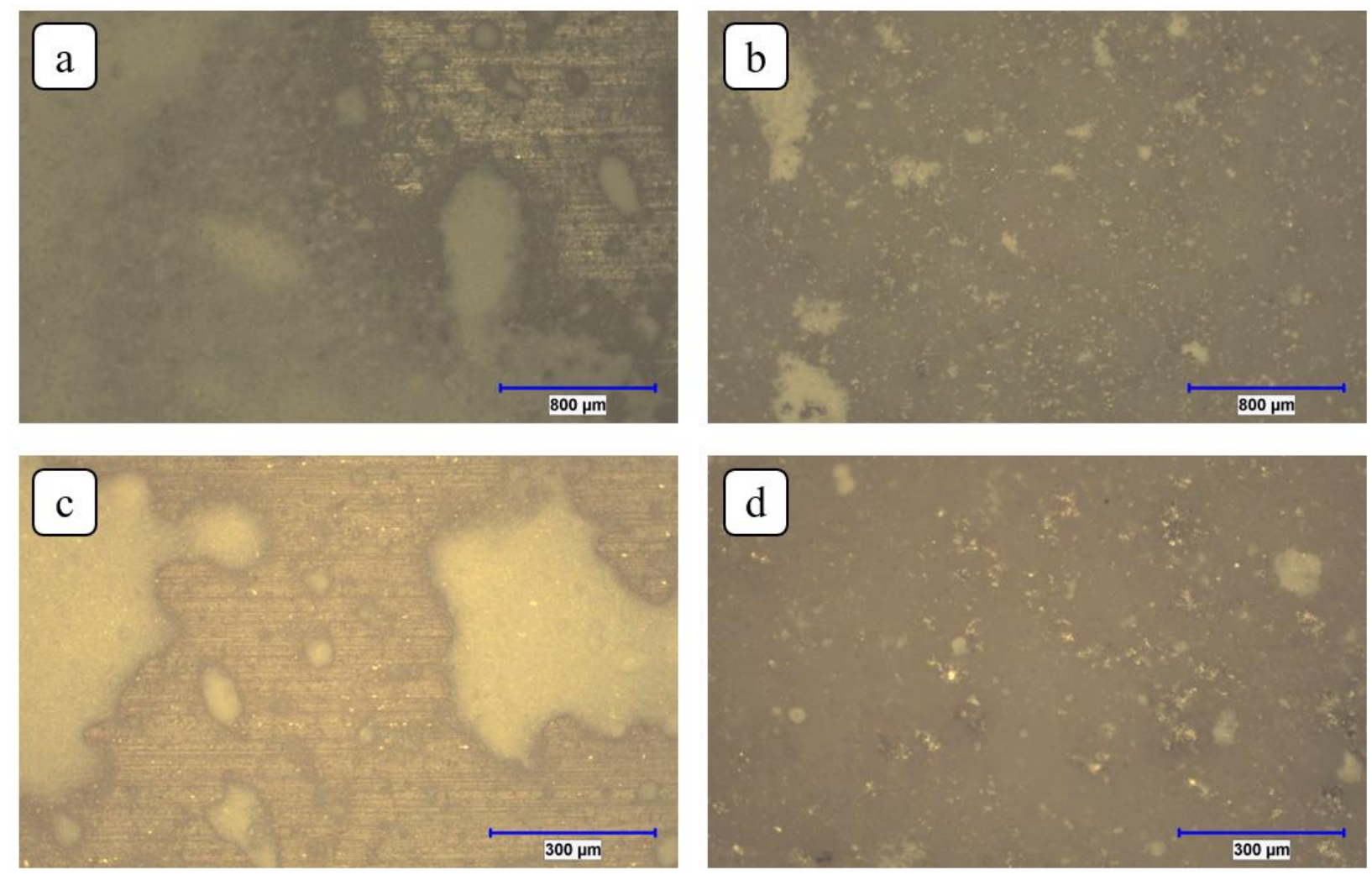

Fig. 21. Optical microscope images of the edges of (a) pristine silicone rubber (PSR) and (b) superhydrophobic silicone rubber (SHSR) surfaces after five spraying cycles, and images of the middle of (c) PSR and (d) SHSR surfaces 
The low molecular weight silicone (LMWS) can diffuse from the bulk of the silicone rubber to the surface, reorient by conformational changes, and then cover the contamination. This leads to hydrophobicity/superhydrophobicity recovery. ${ }^{62,63}$ Benefitting from the hydrophobic-recovery property, and thanks to the self-cleaning property of the SHSR surface, the WCA of the SHSR surface increased to $154.1^{\circ} \pm 1.2^{\circ}$ and $158.2^{\circ} \pm 1.6^{\circ}$; and the CAH decreased to $10^{\circ} \pm 1^{\circ}$ and $8^{\circ} \pm 1^{\circ}$ after one and two weeks, respectively. However, the PSR could not retain its hydrophobicity due to the marked accumulation of contaminants on its surface. The WCA and CAH of PSR had no considerable change after one week. After two weeks, the WCA of the PSR surface increased to $81^{\circ} \pm 4^{\circ}$, and its CAH decreased to $52^{\circ} \pm 2^{\circ}$.

\section{Conclusion}

We produced an ultra-water-repellent silicone rubber having a $\mathrm{WCA}>150^{\circ}$ and a $\mathrm{CAH}<10^{\circ}$ using a straightforward industry-applicable method. We used the compression molding system as an industrialized means to produce silicone rubber surfaces, and we used molding inserts to replicate the micronanostructures on the silicone rubber surfaces as a means for mass production. As the transition from the Cassie-Baxter regime to the Wenzel regime is the main factor in determining the self-cleaning ability of a superhydrophobic surface, we first conducted a series of experiments to investigate the dominance and robustness of the Cassie-Baxter regime. These tests included assessment of the droplet impacting process, droplet evaporation, water-jet impact, trapped air layer, and a severe droplet contact tests. These tests confirmed the ultra-water repellency of the surfaces as well as the consistency of the created micro-nano air pockets in between the surface asperities. To address a lack of comprehensive testing of the waterrepellency and the self-cleaning nature of developed superhydrophobic surfaces, we undertook a comprehensive set of experiments using various contaminants and several methods for applying the contaminants and cleaning the surface, under both wet and dry scenarios. The test conditions were inspired by actual outdoor conditions to which electrical insulators, for example, are exposed. We sprayed a kaolin solution on PSR and SHSR surfaces and dried and redeposited contaminants via spraying. The maintained ultra-low $\mathrm{CAH}$ of the surfaces ensured that the self-cleaning properties remained robust for all tests.

\section{References}

1. Boinovich, L.; Emelyanenko, A. M.; Pashinin, A. S., Analysis of long-term durability of superhydrophobic properties under continuous contact with water. ACS applied materials \& interfaces 2010, 2 (6), 1754-1758.

2. Xue, C.-H.; Ma, J.-Z., Long-lived superhydrophobic surfaces. Journal of Materials Chemistry A 2013, 1 (13), 4146-4161.

3. Verho, T.; Bower, C.; Andrew, P.; Franssila, S.; Ikkala, O.; Ras, R. H., Mechanically durable superhydrophobic surfaces. Advanced Materials 2011, 23 (5), 673-678. 
4. Maghsoudi, K.; Jafari, R.; Momen, G.; Farzaneh, M., Micro-nanostructured polymer surfaces using injection molding: A review. Materials today communications 2017, 13, 126-143.

5. Maghsoudi, K.; Motahari, S., Mechanical, thermal, and hydrophobic properties of silica aerogelepoxy composites. Journal of Applied Polymer Science 2018, 135 (3), 45706.

6. Jafari, R.; Momen, G.; Farzaneh, M., Durability enhancement of icephobic fluoropolymer film. Journal of Coatings Technology and Research 2016, 13 (3), 405-412.

7. Momen, G.; Farzaneh, M., Facile approach in the development of icephobic hierarchically textured coatings as corrosion barrier. Applied Surface Science 2014, 299, 41-46.

8. Jafari, R.; Momen, G.; Eslami, E., Fabrication of icephobic aluminium surfaces by atmospheric plasma jet polymerisation. Surface Engineering 2018, 1-6.

9. Mobarakeh, L. F.; Jafari, R.; Farzaneh, M., Robust icephobic, and anticorrosive plasma polymer coating. Cold Regions Science and Technology 2018, 151, 89-93.

10. Maghsoudi, K.; Momen, G.; Jafari, R.; Farzaneh, M.; Carreira, T. In Micro-Nanostructured

Silicone Rubber Surfaces Using Compression Molding, Materials Science Forum, Trans Tech Publ: 2018; pp 1802-1807.

11. Vazirinasab, E.; Jafari, R.; Momen, G.; Carreira, T. In Simple Fabrication of Superhydrophobic Surfaces Using Atmospheric-Pressure Plasma, Materials Science Forum, Trans Tech Publ: 2018; pp $1808-1814$.

12. Vazirinasab, E.; Jafari, R.; Momen, G., Application of superhydrophobic coatings as a corrosion barrier: A review. Surface and Coatings Technology 2017.

13. Jafari, R.; Farzaneh, M., Development a simple method to create the superhydrophobic composite coatings. Journal of Composite Materials 2013, 47 (25), 3125-3129.

14. Wenzel, R. N., Resistance of solid surfaces to wetting by water. Industrial \& Engineering Chemistry 1936, 28 (8), 988-994.

15. Cassie, A.; Baxter, S., Wettability of porous surfaces. Transactions of the Faraday society 1944, 40, 546-551.

16. Cheng, Y. T.; Rodak, D.; Wong, C.; Hayden, C., Effects of micro-and nano-structures on the self-cleaning behaviour of lotus leaves. Nanotechnology 2006, 17 (5), 1359.

17. Jung, Y. C.; Bhushan, B., Dynamic effects induced transition of droplets on biomimetic superhydrophobic surfaces. Langmuir 2009, 25 (16), 9208-9218.

18. LeClear, S.; LeClear, J.; Park, K.-C.; Choi, W., Drop impact on inclined superhydrophobic surfaces. Journal of colloid and interface science 2016, 461, 114-121.

19. Li, X.; Zhang, L.; Ma, X.; Zhang, H., Dynamic characteristics of droplet impacting on prepared hydrophobic/superhydrophobic silicon surfaces. Surface and Coatings Technology 2016, 307, 243-253.

20. Ramachandran, R., Effects of surface topography and vibrations on wetting:

Superhydrophobicity, icephobicity and corrosion resistance. 2016.

21. Zhang, X.; Tan, S.; Zhao, N.; Guo, X.; Zhang, X.; Zhang, Y.; Xu, J., Evaporation of sessile water droplets on superhydrophobic natural lotus and biomimetic polymer surfaces. ChemPhysChem 2006, 7 (10), 2067-2070.

22. McHale, G.; Aqil, S.; Shirtcliffe, N.; Newton, M.; Erbil, H. Y., Analysis of droplet evaporation on a superhydrophobic surface. Langmuir 2005, 21 (24), 11053-11060.

23. Jung, Y.; Bhushan, B., Wetting behaviour during evaporation and condensation of water microdroplets on superhydrophobic patterned surfaces. Journal of microscopy 2008, 229 (1), 127-140.

24. Dash, S.; Garimella, S. V., Droplet evaporation dynamics on a superhydrophobic surface with negligible hysteresis. Langmuir 2013, 29 (34), 10785-10795.

25. Chu, D.; Nemoto, A.; Ito, H., Enhancement of dynamic wetting properties by direct fabrication on robust micro-micro hierarchical polymer surfaces. Applied Surface Science 2014, 300, 117-123.

26. Liu, S.; Liu, X.; Latthe, S. S.; Gao, L.; An, S.; Yoon, S. S.; Liu, B.; Xing, R., Self-cleaning transparent superhydrophobic coatings through simple sol-gel processing of fluoroalkylsilane. Applied Surface Science 2015, 351, 897-903. 
27. Latthe, S. S.; Sudhagar, P.; Ravidhas, C.; Christy, A. J.; Kirubakaran, D. D.; Venkatesh, R.; Devadoss, A.; Terashima, C.; Nakata, K.; Fujishima, A., Self-cleaning and superhydrophobic CuO coating by jet-nebulizer spray pyrolysis technique. CrystEngComm 2015, 17 (13), 2624-2628.

28. Gurav, A. B.; Xu, Q.; Latthe, S. S.; Vhatkar, R.; Liu, S.; Yoon, H.; Yoon, S. S., Superhydrophobic coatings prepared from methyl-modified silica particles using simple dip-coating method. Ceramics International 2015, 41 (2), 3017-3023.

29. Yoon, H.; Kim, H.; Latthe, S. S.; Kim, M.-w.; Al-Deyab, S.; Yoon, S. S., A highly transparent self-cleaning superhydrophobic surface by organosilane-coated alumina particles deposited via electrospraying. Journal of Materials Chemistry A 2015, 3 (21), 11403-11410.

30. He, Z.; Ma, M.; Xu, X.; Wang, J.; Chen, F.; Deng, H.; Wang, K.; Zhang, Q.; Fu, Q., Fabrication of superhydrophobic coating via a facile and versatile method based on nanoparticle aggregates. Applied Surface Science 2012, 258 (7), 2544-2550.

31. Qiang, S.; Chen, K.; Yin, Y.; Wang, C., Robust UV-cured superhydrophobic cotton fabric surfaces with self-healing ability. Materials \& Design 2017, 116, 395-402.

32. Sheng, X.; Zhang, J., Air layer on superhydrophobic surface underwater. Colloids and Surfaces A: Physicochemical and Engineering Aspects 2011, 377 (1-3), 374-378.

33. Zhang, Y.-L.; Xia, H.; Kim, E.; Sun, H.-B., Recent developments in superhydrophobic surfaces with unique structural and functional properties. Soft Matter 2012, 8 (44), 11217-11231.

34. Latthe, S. S.; Sudhagar, P.; Devadoss, A.; Kumar, A. M.; Liu, S.; Terashima, C.; Nakata, K.; Fujishima, A., A mechanically bendable superhydrophobic steel surface with self-cleaning and corrosionresistant properties. Journal of Materials Chemistry A 2015, 3 (27), 14263-14271.

35. Zheng, S.; Li, C.; Fu, Q.; Hu, W.; Xiang, T.; Wang, Q.; Du, M.; Liu, X.; Chen, Z., Development of stable superhydrophobic coatings on aluminum surface for corrosion-resistant, selfcleaning, and anti-icing applications. Materials \& Design 2016, 93, 261-270.

36. Varshney, P.; Mohapatra, S. S.; Kumar, A., Fabrication of mechanically stable superhydrophobic aluminium surface with excellent self-cleaning and anti-fogging properties. Biomimetics 2017, 2 (1), 2.

37. Bhushan, B.; Jung, Y. C.; Koch, K., Self-cleaning efficiency of artificial superhydrophobic surfaces. Langmuir 2009, 25 (5), 3240-3248.

38. Toma, M.; Loget, G.; Corn, R. M., Flexible teflon nanocone array surfaces with tunable superhydrophobicity for self-cleaning and aqueous droplet patterning. ACS applied materials \& interfaces 2014, 6 (14), 11110-11117.

39. Barthlott, W.; Neinhuis, C., Purity of the sacred lotus, or escape from contamination in biological surfaces. Planta 1997, 202 (1), 1-8.

40. Parkin, I. P.; Palgrave, R. G., Self-cleaning coatings. Journal of materials chemistry 2005, 15 (17), 1689-1695.

41. Zhang, M.; Feng, S.; Wang, L.; Zheng, Y., Lotus effect in wetting and self-cleaning. Biotribology 2016, 5, 31-43.

42. Jung, Y. C.; Bhushan, B., Mechanically durable carbon nanotube- composite hierarchical structures with superhydrophobicity, self-cleaning, and low-drag. ACS nano 2009, 3 (12), 4155-4163.

43. Bagheri, H.; Aliofkhazraei, M.; Forooshani, H. M.; Rouhaghdam, A. S., Facile fabrication of uniform hierarchical structured (UHS) nanocomposite surface with high water repellency and selfcleaning properties. Applied Surface Science 2018, 436, 1134-1146.

44. Momen, G.; Farzaneh, M.; Nekahi, A., Properties and applications of superhydrophobic coatings in high voltage outdoor insulation: A review. IEEE Transactions on Dielectrics and Electrical Insulation 2017, 24 (6), 3630-3646.

45. Charalampidis, P.; Albano, M.; Griffiths, H.; Haddad, A.; Waters, R. T., Silicone rubber insulators for polluted environments part 1: enhanced artificial pollution tests. IEEE Transactions on Dielectrics and Electrical Insulation 2014, 21 (2), 740-748.

46. Maghsoudi, K.; Momen, G.; Jafari, R.; Farzaneh, M.; Carreira, T. In Micro-Nanostructured Silicone Surfaces for Highvoltage Application, 2018 IEEE Conference on Electrical Insulation and Dielectric Phenomena (CEIDP), IEEE: 2018; pp 179-182. 
47. Vazirinasab, E.; Jafari, R.; Momen, G. In Wetting and Self-Cleaning Properties of Silicone Rubber Surfaces Treated by Atmospheric Plasma Jet, 2018 IEEE Conference on Electrical Insulation and Dielectric Phenomena (CEIDP), IEEE: 2018; pp 239-242.

48. IEC, I. E. C. J. I. S., Artificial pollution tests on high-voltage insulators to be used on AC systems. 1991, 507.

49. Dong, B.; Jiang, X.; Hu, J.; Shu, L.; Sun, C., Effects of artificial polluting methods on AC flashover voltage of composite insulators. IEEE Transactions on Dielectrics and Electrical Insulation 2012, 19 (2).

50. Swift, D.; Spellman, C.; Haddad, A., Hydrophobicity transfer from silicone rubber to adhering pollutants and its effect on insulator performance. IEEE Transactions on Dielectrics and Electrical Insulation 2006, 13 (4), 820-829.

51. Gutman, I.; Dernfalk, A., Pollution tests for polymeric insulators made of hydrophobicity transfer materials. IEEE Transactions on Dielectrics and Electrical Insulation 2010, 17 (2).

52. $\quad$ Eisenberg, D.; Laustsen, S.; Stege, J. J. W. E., Wind turbine blade coating leading edge rain erosion model: Development and validation. 2018.

53. Maghsoudi, K.; Momen, G.; Jafari, R.; Farzaneh, M., Direct replication of micro-nanostructures in the fabrication of superhydrophobic silicone rubber surfaces by compression molding. Applied Surface Science 2018.

54. Momen, G.; Farzaneh, M. J. A. S. S., Facile approach in the development of icephobic hierarchically textured coatings as corrosion barrier. 2014, 299, 41-46.

55. $\quad$ Fu, S.-P.; Sahu, R. P.; Diaz, E.; Robles, J. R.; Chen, C.; Rui, X.; Klie, R. F.; Yarin, A. L.; Abiade, J. T., Dynamic study of liquid drop impact on supercooled cerium dioxide: anti-icing behavior. Langmuir 2016, 32 (24), 6148-6162.

56. Rotenberg, Y.; Boruvka, L.; Neumann, A., Determination of surface tension and contact angle from the shapes of axisymmetric fluid interfaces. Journal of colloid and interface science 1983, 93 (1), 169-183.

57. Boyce, J.; Schürch, S.; Rotenberg, Y.; Neumann, A., The measurement of surface and interfacial tension by the axisymmetric drop technique. Colloids and surfaces 1984, 9 (4), 307-317.

58. Girault, H.; Schiffrin, D.; Smith, B., The measurement of interfacial tension of pendant drops using a video image profile digitizer. Journal of colloid and interface science 1984, 101 (1), 257-266.

59. Kulinich, S.; Farzaneh, M., Effect of contact angle hysteresis on water droplet evaporation from super-hydrophobic surfaces. Applied Surface Science 2009, 255 (7), 4056-4060.

60. Inoue, K.; Yamaguchi, A., Synthesis of Al4SiC4. Journal of the American Ceramic Society 2003, $86(6), 1028-1030$.

61. Mgbemena, C. O.; Ibekwe, N. O.; Sukumar, R.; Menon, A. R., Characterization of kaolin intercalates of oleochemicals derived from rubber seed (Hevea brasiliensis) and tea seed (Camelia sinensis) oils. Journal of King Saud University-Science 2013, 25 (2), 149-155.

62. Yan, Z.; Liang, X.; Wu, C.; Bao, W.; Li, S.; Liu, Y. In Aging and recovery of superhydrophobic silicone rubber under electrical and non-electrical stresses, Electrical Insulation and Dielectric Phenomena (CEIDP), 2015 IEEE Conference on, IEEE: 2015; pp 189-192.

63. Hillborg, H.; Gedde, U. J. P., Hydrophobicity recovery of polydimethylsiloxane after exposure to corona discharges. 1998, 39 (10), 1991-1998. 